NASA CONTRACTOR REPORT

(NASA-CF-179222) A MUITIEIE-T1EE-SCALE

N8 8-12754

TUEBULENCE MODEL EASEL CN VAFIAELE

EABTITICNING OF TLRBOIENT KINETIC ENERGI

SECCTBUM Final Refort (Universities Space

FEsearch Assc(iation) 42 F

Unclas

NASA CR-179222

\title{
A MULTIPLE-TIME-SCALE TURBULENCE MODEL BASED ON VARIABLE PARTITIONING OF TURBULENT KINETIC ENERGY SPECTRUM
}

By S. -W. Kim

Universities Space Research Association

Systems Dynamics Laboratory

Science and Engineering Directorate

and

C. $-P$. Chen

Department of Mechanical Engineering

University of Alabama in Huntsville

Huntsville, Alabama 35899

Final Report

November 1987

Prepared for

NASA-Marshall Space Flight Center

Marshall Space Flight Center, Alabama 35812 


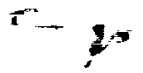




\begin{tabular}{|l|l|}
\begin{tabular}{|l} 
1. REPORT NO. \\
NASA CR- 179222
\end{tabular} & 2. GOVERNMENT ACCESSION NO. \\
\hline 4. TITLE AND SUBTITLE \\
A Multiple-Time-Scale Turbulence Model Based on Variable \\
Partitioning of Turbulent Kinetic Energy Spectrum
\end{tabular}

7. AUTHOR(S)

S. -W. Kim* and C. -P. Chen**

9. PERFORMING ORGANIZATION NAME AND ADDRESS

George C. Marshall Space Flight Center

Marshall Space Flight Center, Alabama 35812

12. SPONSORING AGENCY NAME AND ADORESS

National Aeronautics and Space Administration

Washington, D.C. 20546

15. SUPPLEMENTARY NOTES Contract Monitor: N. C. Costes, Systems Dynamics Lab., Marshaff Mpace Fight Center

*Universities Space Research Association

$\star \star$ Dept . of Mechanical Engineering, University of Alabama in Huntsville.

16. ABSTRACT

A multiple-time-scale turbulence model of a single point closure and a simplified split-spectrum method is presented in this paper. In the model, the effect of the ratio of the production rate to the dissipation rate on eddy viscosity is modeled by use of the multiple-time-scales and a variable partitioning of the turbulent kinetic energy spectrum. The concept of a variable partitioning of the turbulent kinetic energy spectrum and the rest of the model details are based on the previously reported algebraic stress turbulence model. Example problems considered include: a fully developed channel flow, a plane jet exhausting into a moving stream, a wall jet flow, and a weekly coupled wake-boundary layer interaction flow. The computational results compared favorably with those obtained by using the algebraic stress turbulence model as well as experimental data. The present turbulence model, as well as the algebraic stress turbulence model, yielded significantly improved computational results for the complex turbulent boundary layer flows, such as the wall jet flow and the wake-boundary layer interaction flow, compared with available computational results obtained by using the standard $k-\varepsilon$ turbulence model.

17. KEY WORDS Multiple-Time-Scale Turbulence Model, Algebraic Stress Turbulence Model, Turbulent Wall Jet, Turbulent WakeBoundary Layer Interaction Flow, Turbulent Backward-Facing Step Flow, Confined Swirling Jet, Finite Element Method, ControlVolume Based Finite Difference Method
18. OISTRIBUTION STATEMENT

Unclassified/Unlimited
20. SECURITY CLAS SIF. (ot thin pago)

Unclassified

\begin{tabular}{|c|c|c|c|}
\hline $\begin{array}{c}\text { 19. SECURITY CLASSIF. ( } \alpha \text { thlo soport) } \\
\text { Unclassified }\end{array}$ & $\begin{array}{c}\text { 20. SECURITY CLASSIF. (ot thi pago) } \\
\text { Unclassified }\end{array}$ & $\begin{array}{c}\text { 21. NO. OF PAGES } \\
41\end{array}$ & $\begin{array}{l}\text { 22. PRICE } \\
\text { NTIS }\end{array}$ \\
\hline
\end{tabular}




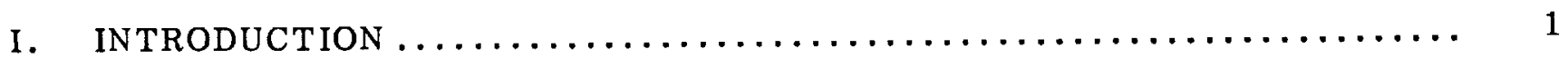

II. MULTIPLE-TIME-SCALE TURBULENCE MODEL.................. 2

$2-1$. Turbulence Equations................................... 2

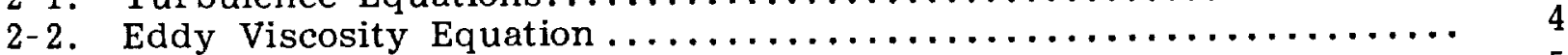

2-3. Wall Function Boundary Conditions........................ 5

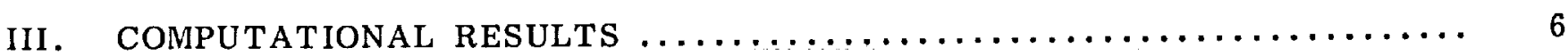

3-1. A Fully Developed Channel Flow ......................... 6

3-2. A Plane Jet Exhausting into a Moving Stream $\ldots \ldots \ldots \ldots \ldots \ldots \ldots \ldots,{ }_{8}$

3-3. A Wall Jet Issuing into a Moving Stream $\ldots \ldots \ldots \ldots \ldots \ldots \ldots \ldots \ldots, 11$

3-4. A Wake-Boundary Layer Interaction Flow $\ldots \ldots \ldots \ldots \ldots \ldots \ldots \ldots, 14$

IV. CONCLUSIONS AND DISCUSSION $\ldots \ldots \ldots \ldots \ldots \ldots \ldots \ldots \ldots \ldots \ldots \ldots \ldots \ldots \ldots \ldots \ldots \ldots$

APPENDIX I. THE TURBULENCE MODEL CONSTANTS $\ldots \ldots \ldots \ldots \ldots \ldots \ldots . . \ldots \ldots$

A-1-1. Free Stream Turbulence $\ldots \ldots \ldots \ldots \ldots \ldots \ldots \ldots \ldots \ldots \ldots, 17$

A-1-2. Near Wall Equilibrium Flow $\ldots \ldots \ldots \ldots \ldots \ldots \ldots \ldots \ldots \ldots, 19$

A-1-3. Homogeneous Turbulent Shear Flow $\ldots \ldots \ldots \ldots \ldots \ldots \ldots \ldots \ldots, 20$

APPENDIX II. A CONTROL-VOLUME BASED FINITE DIFFERENCE COMPUTATION OF SEPARATED AND SWIRLING

TURBULENT FLOWS $\ldots \ldots \ldots \ldots \ldots \ldots \ldots \ldots \ldots \ldots \ldots, 23$

A-2-1. A Turbulent Backward-Facing Step Flow $\ldots \ldots \ldots \ldots \ldots \ldots \ldots .23$

A-2-2. A Confined Swirling Jet $\ldots \ldots \ldots \ldots \ldots \ldots \ldots \ldots \ldots \ldots \ldots \ldots \ldots \ldots \ldots \ldots \ldots \ldots \ldots \ldots, 28$ 


\section{LIST OF ILLUSTRATIONS}

Figure

Title

Page

1. Description and nomenclature of the multiple-time-scale

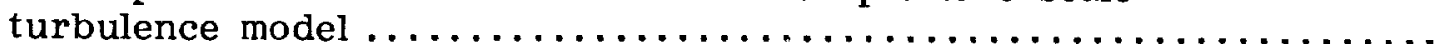

2. A fully developed channel flow $\ldots \ldots \ldots \ldots \ldots \ldots \ldots \ldots \ldots \ldots \ldots \ldots \ldots$

(a) Velocity, turbulent kinetic energy, and Reynolds stress

(b) Dissipation rate, $\mathrm{k}_{\mathrm{t}} / \mathrm{k}_{\mathrm{p}}$, and $\varepsilon_{\mathrm{t}} / \varepsilon_{\mathrm{p}}$

3. A plane jet exhausting into a moving stream $\ldots \ldots \ldots \ldots \ldots \ldots \ldots \ldots \ldots$

(a) Development of the jet along the flow direction

(b) Velocity, turbulent kinetic energy, and Reynolds stress at $\mathrm{x}=0.381 \mathrm{~m}$

(c) Dissipation rate, $k_{t} / k_{p}$, and $E_{t} / \varepsilon_{p}$ at $x=0.381 \mathrm{~m}$

(d) Velocity, turbulent kinetic energy and Reynolds stress at $\mathrm{x}=0.650 \mathrm{~m}$

(e) Dissipation rate, $\mathrm{k}_{\mathrm{t}} / \mathrm{k}_{\mathrm{p}}$, and $\varepsilon_{\mathrm{t}} / \varepsilon_{\mathrm{p}}$ at $\mathrm{x}=0.650 \mathrm{~m}$

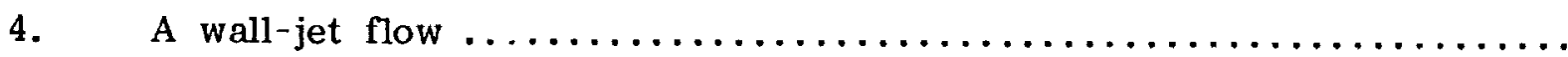

(a) Development of the wall-jet flow along the flow direction

(b) Velocity, turbulent kinetic energy, and Reynolds stress at $\mathrm{x}=1.1532 \mathrm{~m}$

(c) Dissipation rate, $k_{t} / k_{p}$, and $\varepsilon_{t} / \varepsilon_{p}$ at $x=1.1532 \mathrm{~m}$

(d) Velocity, turbulent kinetic energy, and Reynolds stress at $\mathrm{x}=1.6882 \mathrm{~m}$

(e) Dissipation rate, $\mathrm{k}_{\mathrm{t}} / \mathrm{k}_{\mathrm{p}}$ and $\varepsilon_{\mathrm{t}} / \varepsilon_{\mathrm{p}}$ at $\mathrm{x}=1.6882 \mathrm{~m}$

5. A wake-boundary layer interaction flow $\ldots \ldots \ldots \ldots \ldots \ldots \ldots \ldots \ldots$

(a) Velocity, turbulent kinetic energy, and Reynolds stress at $\mathrm{x}=0.40 \mathrm{~m}$

(b) Dissipation rate, $k_{t} / k_{p}$, and $\varepsilon_{t} / \varepsilon_{p}$ at $x=0.40 \mathrm{~m}$

(c) Velocity, turbulent kinetic energy, and Reynolds stress at $\mathrm{x}=0.86 \mathrm{~m}$

(d) Dissipation rate, $\mathrm{k}_{\mathrm{t}} / \mathrm{k}_{\mathrm{p}}$, and $\varepsilon_{\mathrm{t}} / \varepsilon_{\mathrm{p}}$ at $\mathrm{x}=0.86 \mathrm{~m}$

A.1 Streamline contour for backward-facing step flow ............. 24

A.2. Turbulent kinetic energy contour for backward-facing

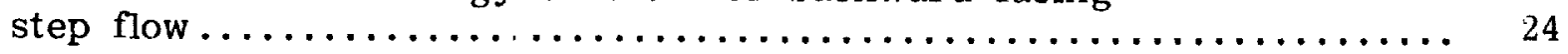

A.3. Velocity profiles for backward-facing step flow $\ldots \ldots \ldots \ldots \ldots \ldots \ldots$

A.4. Turbulent kinetic energy profiles for backward-facing

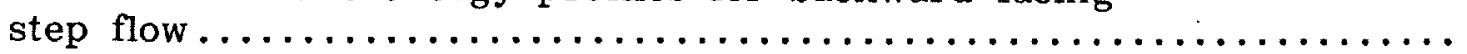

A.5. Reynolds stress profiles for backward-facing step flow.......... 26 


\section{LIST OF ILLUSTRATIONS (Concluded)}

Figure

Title

Page

A.6. The ratio of dissipation rate to energy transfer rate for the backward-facing step flow.

A.7. Streamline contour for backward-facing step flow,

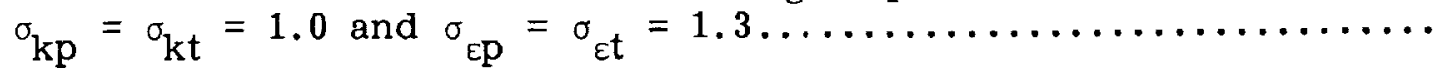

A.8. Turbulent kinetic energy contour for backward-facing step flow,

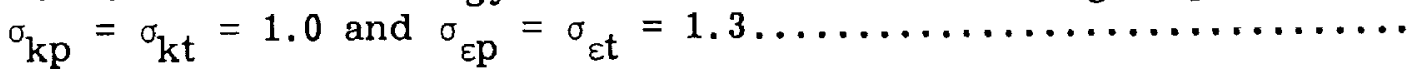

A.9. Streamline contour for confined swirling jet................ 29

A. 10. Turbulent kinetic energy contour for confined swirling jet ........ 29

A.11. Development of the axial mean velocity along the center line for

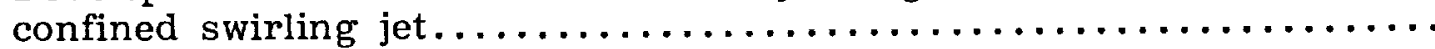

A.12. Axial velocity profiles of the confined swirling jet ............ 30

A.13. Swirl velocity profiles of the confined swirling jet $\ldots \ldots \ldots \ldots \ldots \ldots \ldots$

A.14. R.M.S. values of the fluctuating axial velocity $\ldots \ldots \ldots \ldots \ldots \ldots \ldots \ldots . . . .31$

A.15. The ratio of dissipation rate to energy transfer rate for

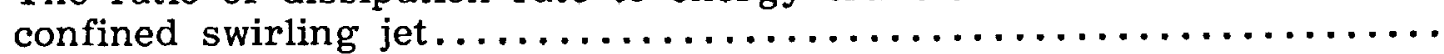

A.16. Streamline contour for confined swirling jet,

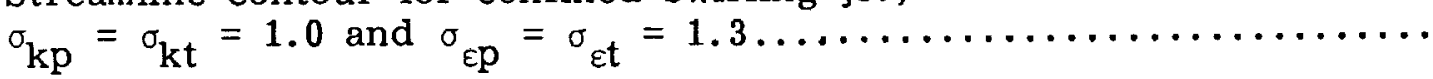

A.17. Turbulent kinetic energy contour for confined swirling jet, $\sigma_{\mathrm{kp}}=\sigma_{\mathrm{kt}}=1.0$ and $\sigma_{\varepsilon p}=\sigma_{\varepsilon t}=1.3 \ldots \ldots \ldots \ldots \ldots \ldots \ldots \ldots \ldots$ 


\section{LIST OF TABLES}

Table

Title

Page

A.1. Contour Labels for Backward-Facing Step Flow $\ldots \ldots \ldots \ldots \ldots \ldots \ldots \ldots$

(a) Streamline $(\psi)$

(b) Turbulent Kinetic Energy (k)

A.2. Contour Labels for Confined Swirling Jet $\ldots \ldots \ldots \ldots \ldots \ldots \ldots \ldots \ldots \ldots$

(a) Streamline $(\psi)$

(b) Turbulent Kinetic Energy (k) 


\title{
CONTRACTOR REPORT
}

\author{
A MULTIPLE-TIME-SCALE TURBULENCE MODEL BASED ON VARIABLE \\ PARTITIONING OF TURBULENT KINETIC ENERGY SPECTRUM
}

\section{INTRODUCTION}

In turbulent flows, instability of mean flow generates large eddies, the large eddies break up into smaller eddies, and the fine scale eddies are dissipated by viscous force. The multiple-time-scale turbulence model is derived by partitioning the turbulent kinetic energy spectrum into a set of wave number regions, integrating the partitioned energy spectral density equation to obtain energy evolution for each of the wave number regions, and considering the energy flux rate between adjacent wave number regions. Therefore, the generation, cascade, and dissipation of turbulent kinetic energy are considered in the multiple-time-scale turbulence model; whereas, only the generation and the dissipation of turbulent kinetie energy are considered in the classical turbulence models such as the $\mathrm{k}^{-} \varepsilon$ turbulence models and the Reynolds stress turbulence models.

A few papers on the multiple-time-scale turbulence model have appeared recently. The multiple-time-scale turbulence model used in Hanjelic et al. [1] and Fabris et al. [2] are based on the simplified split-spectrum method. Generalization of the model for multiple split-spectrum case and extension of the multiple-time-scale concept to convection-diffusion of scalar variables is given in Schiestel [3,4]. The multiple-time-scale turbulence model presented herein is based on the simplified splitspectrum method and variable partition of the turbulent kinetic spectrum. The rest of the model details are based on the algebraic stress turbulence model given in References 5 through 7 , among many others.

Uniform division of the turbulent kinetic energy spectrum has been used in the multiple-time-scale turbulence models proposed in References 1 through 4 . A difficulty may arise in this case, since the turbulence field of complex turbulent flows is characterized by inhomogeneous turbulent kinetic energy spectrum distributed in a wide range of wave numbers. If the partition is moved to too high wave numbers, then the multiple-scale turbulence model may reduce to a single scale model, on the other hand, if the partition is moved to too low wave numbers, then production of turbulent kinetic energy will be contained in the dissipation range which is contradictory to the multiple-time-scale concept [1-4]. This difficulty can be eliminated by using a variable partitioning of the turbulent kinetic energy spectrum in such a way that the partition is moved to the high wave number direction when production is high, and that the partition is moved to the low wave number direction when production vanishes. In the present turbulence mdoel, the partitioning of the turbulent kinetic energy spectrum is dependent on the turbulence intensities, production rate, energy transfer rate, and dissipation rate, and is determined as a part of the solution. Furthermore, the variable partitioning method rendered the effective eddy viscosity coefficient to decrease when produciton is high and to increase when production vanishes. The same effect of the production rate on the eddy viscosity coefficient can be found in experimental data [8] as well as in algebraic stress turbulence models [5-7].

The turbulent boundary layer flows considered herein were solved by a finite element method $[5,9,10]$. It has been shown in Reference 10 that the finite element 
method could solve a wide range of laminar boundary layer flows, such as the Blasius flat plate flow, the retarded Howarth flow, flow over a wedge, plane stagnation flow, flow over a circular cylinder, flow in the wake of a flat plate, uniform suction flow over a flat plate, flow over a cone, and flow over a sphere, as accurately as any available numerical methods including the semi-analytical methods. The numerical details on turbulence equations can be found in Reference 5 .

Establishment of the turbulence model constants is discussed in Appendix I. Use of the present turbulence model in finite difference computation of elliptic turbulent flows improved the computational results in comparison with those obtained by using the standard $\mathrm{k}-\varepsilon$ turbulence model as can be found in Appendix II.

\section{MULTIPLE-TIME-SCALE TURBULENCE MODEL}

The turbulent boundary layer flow equations are given as:

$$
\begin{aligned}
& \frac{\partial u}{\partial x}+\frac{\partial v}{\partial y}=0 \\
& u \frac{\partial u}{\partial x}+v \frac{\partial u}{\partial y}-\frac{\partial}{\partial y}\left[\left(v+v_{t}\right) \frac{\partial u}{\partial y}\right]=-\frac{1}{\rho} \frac{d p}{d x}
\end{aligned}
$$

where $\mathrm{u}$ and $\mathrm{v}$ are the time averaged velocities in flow direction and in transverse direction, respectively, $p$ is the pressure, $v$ is the kinematic viscosity of the fluid, and $v_{t}$ is the turbulent eddy viscosity.

\section{2-1. Turbulence Equations}

The underlying idea [1-4] and the nomenclature of the multiple-scale turbulence model is shown in Figure 1, where $k_{p}$ is the turbulent kinetic energy of eddies in the production range, $\mathrm{k}_{\mathrm{t}}$ is the turbulent kinetic energy of eddies in the dissipation range, $\operatorname{Pr}$ is the production rate of turbulent kinetic energy, $k\left(k=k_{p}+k_{t}\right)$ is the total turbulent kinetic energy, $\varepsilon_{p}$ is the transfer rate of turbulent kinetic energy from the production range to the dissipation range, and $\varepsilon_{t}$ is the dissipation rate.

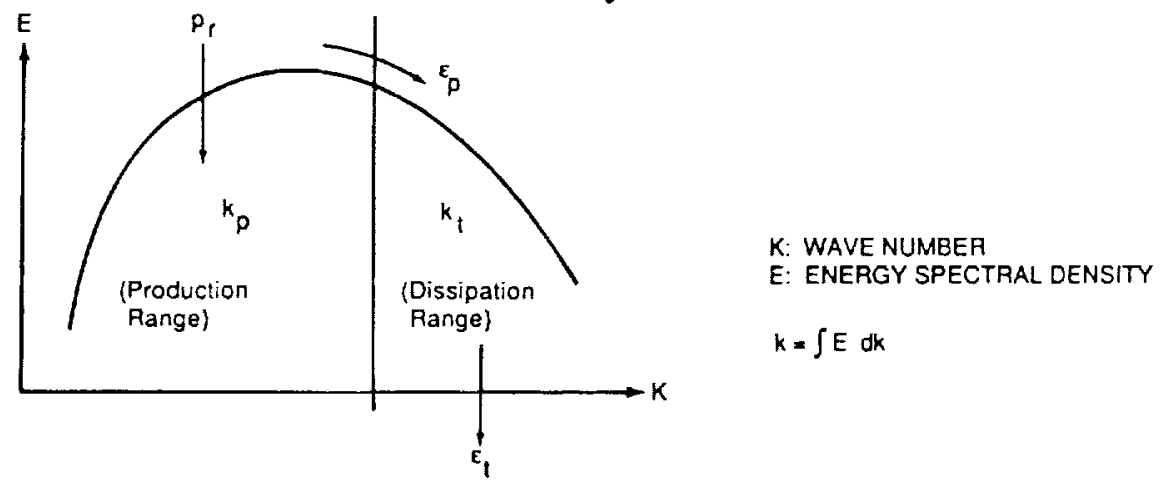

Figure 1. Description and nomenclature of the multiple-time-scale turbulence model. 
Transport equations for the turbulent kinetic energies are given as [1-4]:

$$
\begin{aligned}
& u \frac{\partial k_{p}}{\partial x}+v \frac{\partial k_{p}}{\partial y}-\frac{\partial}{\partial y}\left[\left(\nu+\frac{v_{t}}{\sigma_{k p}}\right) \frac{\partial k_{p}}{\partial y}\right]=\operatorname{Pr}-\varepsilon_{p} \\
& u \frac{\partial k_{t}}{\partial x}+v \frac{\partial k_{t}}{\partial y}-\frac{\partial}{\partial y}\left[\left(\nu+\frac{v_{t}}{\sigma_{k t}}\right) \frac{\partial k_{t}}{\partial y}\right]=\varepsilon_{p}-\varepsilon_{t}
\end{aligned}
$$

where $\sigma_{k p}$ and $\sigma_{k t}$ are constant coefficients.

The convection-diffusion equations for the energy transfer rate and the dissipation rate can be written as, in general:

$$
\begin{aligned}
& \frac{D \varepsilon_{p}}{D t}=f_{p}\left(k, k_{p}, k_{t}, \operatorname{Pr}, \varepsilon_{p}, \varepsilon_{t}\right)+(\text { diffusion term) } \\
& \frac{D \varepsilon_{t}}{\overline{D t}}=f_{t}\left(k, k_{p}, k_{t}, \operatorname{Pr}, \varepsilon_{p}, \varepsilon_{t}\right)+\text { (diffusion term) . }
\end{aligned}
$$

Following the work of Hanjelic et al. [1] and based on the algebraic stress turbulence model [5-6], the influence functions proposed herein are given as $f_{p}=$

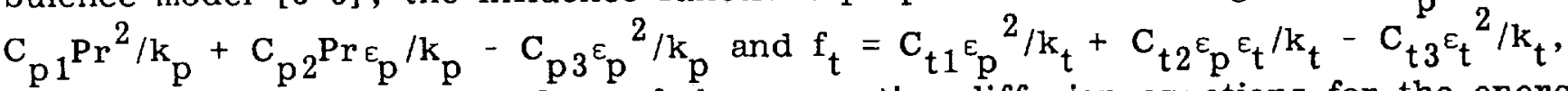
respectively. The complete form of the convection-diffusion equations for the energy transfer rate and the dissipation rate are given as:

$$
\begin{aligned}
& u \frac{\partial \varepsilon_{p}}{\partial x}+v \frac{\partial \varepsilon_{p}}{\partial y}-\frac{\partial}{\partial y}\left[\left(\nu+\frac{\nu_{t}}{\sigma_{\varepsilon p}}\right) \frac{\partial \varepsilon_{p}}{\partial y}\right]=c_{p 1} \frac{\operatorname{Pr}^{2}}{k_{p}}+c_{p 2} \frac{\operatorname{Pr}_{p}}{k_{p}}-c_{p 3} \frac{\varepsilon_{p}^{2}}{k_{p}} \\
& u \frac{\partial \varepsilon_{t}}{\partial x}+v \frac{\partial \varepsilon_{t}}{\partial y}-\frac{\partial}{\partial y}\left[\left(\nu+\frac{\nu_{t}}{\sigma_{\varepsilon t}}\right) \frac{\partial \varepsilon_{t}}{\partial y}\right]=c_{t 1} \frac{\varepsilon_{p}}{k_{t}}+c_{t 2} \frac{\varepsilon_{p} \varepsilon_{t}}{k_{t}}-c_{t 3} \frac{\varepsilon_{t}}{k_{t}}
\end{aligned}
$$

where $\sigma_{\varepsilon p}$ and $\sigma_{\varepsilon t}$ are constant coefficients, $c_{p \ell}(\ell=1,3)$ and $c_{t \ell}(\ell=1,3)$ are turbulence model constants. The $\mathrm{c}_{\mathrm{p} 1} \mathrm{Pr}^{2} / \mathrm{k}_{\mathrm{p}}$ and $\mathrm{c}_{\mathrm{t} 1} \varepsilon_{\mathrm{p}} / \mathrm{k}_{\mathrm{t}}$ terms were obtained from physical dimensional analysis. The first term increases the energy transfer rate when production is high, and the second term increases the dissipation rate when the energy transfer rate is high. Both of these terms are equivalent to the variable energy transfer function proposed in Hanjelic et al. [1], which is given as $-0.3\left(k_{p} / k_{t}-1\right) /$ $\left(\mathrm{k}_{\mathrm{p}} / \mathrm{k}_{\mathrm{t}}+1\right) \varepsilon_{\mathrm{p}}{ }^{2} / \mathrm{k}_{\mathrm{p}}$. It can be shown that the variable energy transfer function proposed 
in Hanjalic et al. is equivalent to those of the present turbulence model, if the ratio of $\mathrm{k}_{\mathrm{p}}$ to $\mathrm{k}_{\mathrm{t}}$ approaches a constant which is determined by the ratio of production rate to dissipation rate as discussed in Appendix I. Further discussion on the variable energy transfer function can be found in Pope [11] and Hanjalic and Launder [12], among many others.

The model constants used in the present study are; $\sigma_{\mathrm{kp}}=0.75, \sigma_{\varepsilon \mathrm{p}}=1.15$, $\sigma_{\mathrm{kt}}=0.75, \sigma_{\varepsilon t}=1.15, c_{\mathrm{p} 1}=0.21, \mathrm{c}_{\mathrm{p} 2}=1.24, \mathrm{c}_{\mathrm{p} 3}=1.84, \mathrm{c}_{\mathrm{t} 1}=0.29, \mathrm{c}_{\mathrm{t} 2}=1.28$, and $c_{t 3}=1.66$.

\section{Eddy Vist sitw Equation}

The exdy viscosity expression proposed herein is given as:

$$
v_{t}=c_{\mu f} k^{2} / \varepsilon_{p}
$$

where $c_{\mu f}(=0.09)$ is a constant. The eddy viscosity equation is equivalent to that of the standard $\mathrm{k}-\varepsilon$ turbulence model except that the dissipation rate $(\varepsilon)$ has been replaced by the energy transfer rate of large eddies. Therefore, the turbulence length scale is related to the energy transfer rate $\left(\varepsilon_{p}\right)$, rather than the dissipation rate $\left(\varepsilon_{t}\right)$.

Experimental data shows that the eddy viscosity coefficient $\left(c_{\mu}\right)$ decreases as the ratio of $\operatorname{Pr} / \varepsilon_{t}$ is increased; and increases as the ratio of $\operatorname{Pr} / \varepsilon_{t}$ is decreased. In algebraic stress turbulence models, the eddy viscosity coefficient $\left(c_{\mu}\right)$ is given as a function of the ratio of production rate to dissipation rate [5-7]. In the present multiple-time-scale turbulence model, which is based on the variable partitioning of the turbulent kinetic energy spectrum method, the $c_{u}$ function is implicitly included in the eddy viscosity equation, i.e.,

$$
\nu_{t}=c_{\mu f} \mathrm{k}^{2} / \varepsilon_{p}=c_{\mu} k^{2} / \varepsilon_{t}
$$

where $c_{\mu}=c_{\mu f} \varepsilon_{t} / \varepsilon_{p}$ is defined to be the effective eddy viscosity coefficient in the following discussions. The ratio of $\varepsilon_{t} / \varepsilon_{p}$ decreases as the ratio of $\operatorname{Pr} / \varepsilon_{t}$ is increased; and increases as the ratio of $\operatorname{Pr} / \varepsilon_{t}$ is decreased. In the near wall regions, the production rate is approximately equal to the dissipation rate, thus the energy transfer rate has to be approximately equal to both of these. In the free stream region where production vanishes, the turbulence model constants given previously yield the value of $\varepsilon_{t} / E_{p}$ to be 2.5 approximately (see Appendix I).

The dissipation rate is weakly coupled with the rest of the turbulence quantities in the multiple-time-scale turbulence model than in the single-time-scale turbulence models such as the $\mathrm{k}-\varepsilon$ type turbulence models. If the multiple-time-scale concept is 
to be justified, then it is expected that the computational result of the dissipation rate $\left(\varepsilon_{t}\right)$ obtained by using the multiple-time-scale turbulence model would be comparable to that obtained by using the single-time-scale turbulence model such as the algebraic stress turbulence model [5-6]. The present computational results showed that the above requirement was very well satisfied.

The eddy viscosity equation proposed by Hanjalic et al., which is given as: $v_{t}=c_{\mu}\left(k_{p}+k_{t}\right) k_{p} / \varepsilon_{p}$, is compatible with the near wall mixing length theory or the standard wall function method only when $\mathrm{k}_{t}$ vanishes in the near wall region. On the other hand, the eddy viscosity expression given in equation (9) is compatible with both the near wall mixing length theory and the wall function method in general.

\section{2-3. Wall Function Boundary Conditions}

The wall function boundary conditions were derived from the standard wall function method [13]. These are given as:

$$
\begin{aligned}
& \frac{\mathrm{u}}{\mathrm{u}_{\mathrm{\tau}}}=\frac{1}{\mathrm{~K}} \ln \left(\mathrm{Ey}^{+}\right) \\
& \tau_{w}=-\left[\rho k c_{\mu}^{1 / 4} k^{1 / 2} / \ln \left(\mathrm{Ey}^{+}\right)\right] u \\
& \mathrm{k}=\mathrm{c}_{\mu}{ }^{-1 / 2} \tau_{\mathrm{w}} / \rho \\
& \varepsilon=\frac{1}{k y} c_{\mu}^{3 / 4} k^{3 / 2} \\
& \frac{\mathrm{k}_{\mathrm{t}}}{\mathrm{k}_{\mathrm{p}}}=\frac{\mathrm{k}^{2}}{\sigma_{\varepsilon \mathrm{p}} \mathrm{c}_{\mu}^{1 / 2}\left(\mathrm{c}_{\mathrm{p} 3}-\mathrm{c}_{\mathrm{p} 1}-\mathrm{c}_{\mathrm{p} 2}\right)}-1 \\
& \frac{\varepsilon_{\mathrm{t}}}{\varepsilon_{\mathrm{p}}}=1
\end{aligned}
$$

where $u^{+}, u^{+}=u / u_{\tau}$, is a non-dimensional velocity, $u_{\tau}, u_{\tau}=V^{\prime}\left(\tau_{w} / \rho\right)$, is the wall friction velocity; $\tau_{w}$ is the wall shearing stress; $\mathrm{y}^{+}, \mathrm{y}^{+}=\mathrm{u}_{\tau} \mathrm{y} / \mathrm{v}$, is the wall coordinate; $\kappa$ is the von Karmann constant; and $E$ is an experimentally determined constant coefficient. $k=0.41$ and $E=9.0$ has been used in the present study. Derivation of equation (15) is given in Appendix I. 


\section{COMPUTATIONAL RESULTS}

The governing differential equations were solved on the physical domain using physical dimensions. Whenever necessary, the values of $1.225 \mathrm{~kg} / \mathrm{m}^{3}$ and $0.17854 \mathrm{x}$ $10^{-4} \mathrm{~kg} / \mathrm{m}$-sec were used for density and molecular viscosity, respectively.

The initial condition data for velocity, turbulent kinetic energy, and dissipation rate were obtained from experimental data [5-6]. The initial condition data for the ratios of $\mathrm{k}_{\mathrm{p}} / \mathrm{k}_{\mathrm{t}}$ and $\varepsilon_{\mathrm{p}} / \varepsilon_{\mathrm{t}}$ were obtained by interpolating the near $w$ all values and the free stream values using an equation of the form:

$$
r=r_{e}+\left(r_{w}-r_{e}\right) d\left(\operatorname{Pr} / \varepsilon_{t}\right)
$$

where $\mathrm{r}$ stands for $\mathrm{k}_{\mathrm{p}} / \mathrm{k}_{\mathrm{t}}$ or $\varepsilon_{\mathrm{p}} / \varepsilon_{\mathrm{t}}$, the subscript e denotes the external free stream value, the subscript $w$ denotes the near wall value, and the production rate was obtained from the experimental data using the relationship that $\operatorname{Pr}=\overline{-u^{\prime} v^{\dagger}}(\partial u / \partial y)$.

The wall function boundary conditions, equations (11-16), were used in the near wall region and the vanishing gradient boundary condition was used at the outer edge of the computational domain for all the cases, unless otherwise specified. Details on the computational procedure can be found in Reference 5 . The convergence criterion used is given as:

$$
\left|\left(a_{j}{ }^{n+1}-a_{j}^{n}\right) / a_{j}{ }^{n+1}\right|<e, j=1, N \text {, no sum on } j
$$

where $a_{j}$ stands for the nodal values of $u, k, \varepsilon_{p}$, or $\varepsilon_{t} ; N$ denotes the total number of degrees of freedom; and $e=1 \times 10^{-7}$ was used.

\section{3-1. Fully Developed Channel Flow}

The experimental data for the fully developed channel flow considered herein can be found in Laufer [14]. The Reynolds number based on the channel half width of $0.0635 \mathrm{~m}$ and the center line mean velocity of $7.07 \mathrm{~m} / \mathrm{sec}$ is approximately 30,800 .

The computational domain extending from $\mathrm{y}=0.005 \mathrm{~m}$ near the wall, which corresponds to $\mathrm{y}^{+}=100$, to $\mathrm{y}=0.0635 \mathrm{~m}$ at the center of the channel was discretized using 20 equally spaced quadratic elements. The Dirichlet boundary conditions for $u$, $k_{p}$ and $k_{t}$ at the near wall region were obtained from experimental data and by using equation (15), whereas the boundary condition for the dissipation rate was obtained from the near wall mixing length theory [5-6]. The near wall boundary conditions used are: $u=5.084 \mathrm{~m} / \mathrm{sec} ; \mathrm{k}=0.213 \mathrm{~m}^{2} / \mathrm{sec}^{2} ; \mathrm{k}_{\mathrm{p}}=0.172 \mathrm{~m}^{2} / \mathrm{sec}^{2} ; \mathrm{k}_{\mathrm{t}}=0.213 \mathrm{~m}^{2} /$ $\sec ^{2}$, and $\varepsilon_{p}=\varepsilon_{t}=10.64 \mathrm{~m}^{2} / \mathrm{sec}^{3}$. 
The flat profiles for the velocity, both of the turbulent kinetic energies, the energy transfer rate, and the dissipation rate were used as initial guess, and the convergence criterion stated earlier was achieved in 150 iterations. The computational results for the velocity, the turbulent kinetic energy, and the Reynolds stress obtained by using the mililiple-time-scale turbulence model are compared with those obtained by using the algebraic stress turbulence model as well as experimental data in Figure 2(a). It can be seer: that the multiple-time-scale turbulence model yielded almost the same computational results as the algebraic stress turbulence model. The dissipation rate obtained by using the multiple-time-scale turbulence model was found to be the same as that of the algebraic stress turbulence model. The ratios of $k_{t} / k_{p}$ and $\varepsilon_{t} / \varepsilon_{p}$ are shown in Figure 2(b). It can be seen in Figure 2(b) that the value of $\varepsilon_{\mathrm{t}} / \varepsilon_{\mathrm{p}}$ is approximately equal to unity, and hence the effective eddy viscosity coefficient $\left(c_{\mu}\right)$ is approximately equal to 0.09 in the entire flow domain.

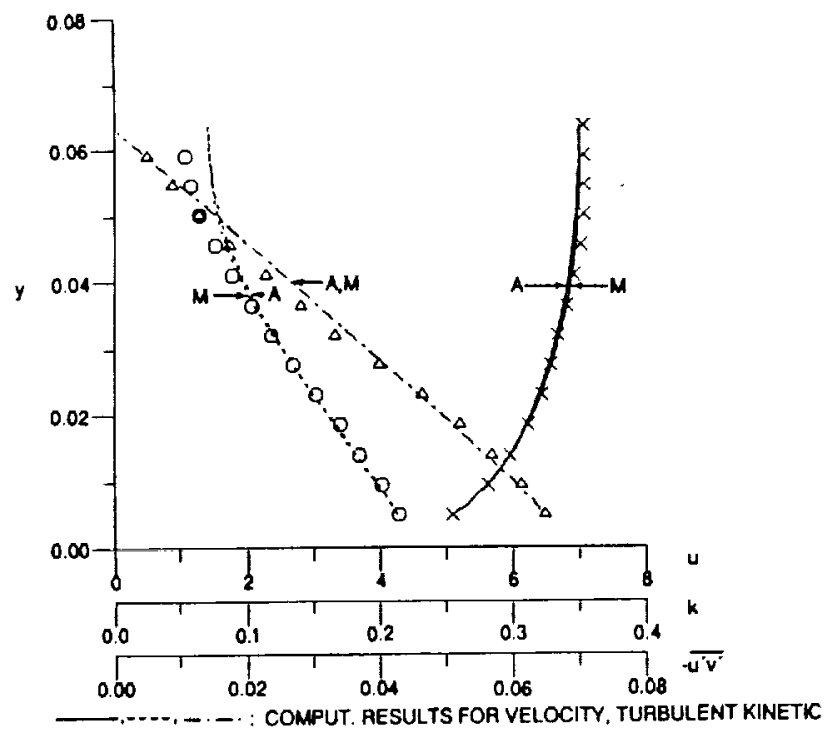

ENERGY, AND REYNOLDS STRESS, $x, 0, \Delta:$ EXPT DATA FOR VELOCITY, TURBULENT KINETIC ENERGY, ANO REYNOLOS STRESS. M: MULTIPLE-TIME-SCALE TURBULENCE MODEL,

A: ALGEBPAIC STRESS TURBULENCE MODEL.

(b)

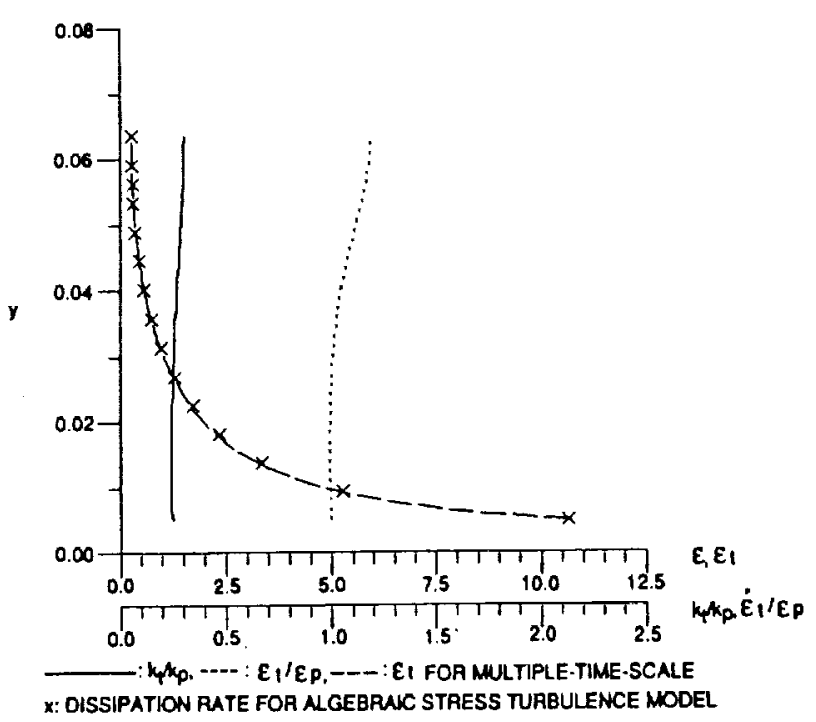

Figure 2. A fully developed channel flow. (a) Velocity, turbulent kinetic energy, and Reynolds stress. (b) Dissipation rate, $\mathrm{k}_{\mathrm{t}} / \mathrm{k}_{\mathrm{p}}$ and $\varepsilon_{\mathrm{t}} / \varepsilon_{\mathrm{p}}$. 


\section{3-2. A Plane Jet Exhausting into a Moving Stream}

A plane jet exhausting into a moving stream is considered below, the experimental data of which can be found in Bradbury [15]. In the following discussions, the half jet width is defined as a distance from the center line of jet to a location where the excess velocity is half of the center line excess velocity.

The computational domain in flow direction starting from $\mathrm{x}=0.095 \mathrm{~m}(\mathrm{x} / \mathrm{d}=10$, $\mathrm{d}=0.009525 \mathrm{~m}$ is the jet exit width) to $\mathrm{x}=0.65 \mathrm{~m}(\mathrm{x} / \mathrm{d}=70)$ was discretized by 580 line-steps; and the transverse domain extending $y=0 \mathrm{~m}$ (center line of the jet) to $\mathrm{y}=0.1 \mathrm{~m}$ (approximately 12.5 times of the half jet width at $\mathrm{x} / \mathrm{d}=10$ ) was discretized by 45 unequally spaced quadratic elements.

Decay of the center line velocity and evolution of the half jet width along the flow direction, obtained by using the two turbulence models, compared favorably with experimental data as shown in Figure 3(a). The computed velocity profile, turbulent kinetic energy profile, and the Reynolds stress are compared with experimental data in Figures 3(b) and 3(d) at two flow-direction locations. These profiles compare more favorably with experimental data at the middle of the flow direction domain than at the downstream end of the computational domain. It can be seen that the multiple-time-scale turbulence model yielded slightly better computational results than the algebraic stress turbulence model at the downstream end of the computational domain. The dissipation rate obtained by using the multiple-time-scale turbulence model compared favorably with that of the algebraic stress turbulence model as shown in Figures $3(\mathrm{c})$ and $3(\mathrm{e})$. The ratio of $\varepsilon_{\mathrm{t}} / \varepsilon_{\mathrm{p}}$ exhibited sharp transition in the viscous super layer (the transition region between the high turbulence region and the free stream low turbulence region), thus the effective eddy viscosity coefficient $\left(c_{\mu}\right.$ ) also changed abruptly, but still smoothly and continuously, in the viscous super layer.

An average of 9 iterations was required to satisfy the previously stated convergence criterion for each line-step.

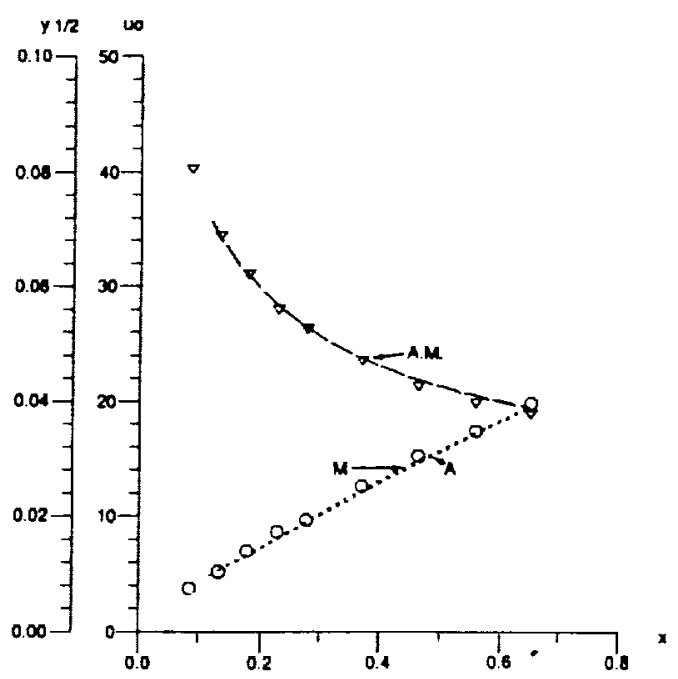

- - -...... . COMPIT CENTER LINE VELOCTY ANO HNLF JET WIOTH, A, O: EXPT CENTER UNE VELOCTY AND HULF JET WIOTH,

M: MNCTIPLE-TME-SCALE TURBULENCE MOOEL, A : ALGEBAAIC STAESS TUREULENCE MOOEL.

(a) Development of the jet along the flow direction.

Figure 3. A plane jet exhausting into a moving stream. 


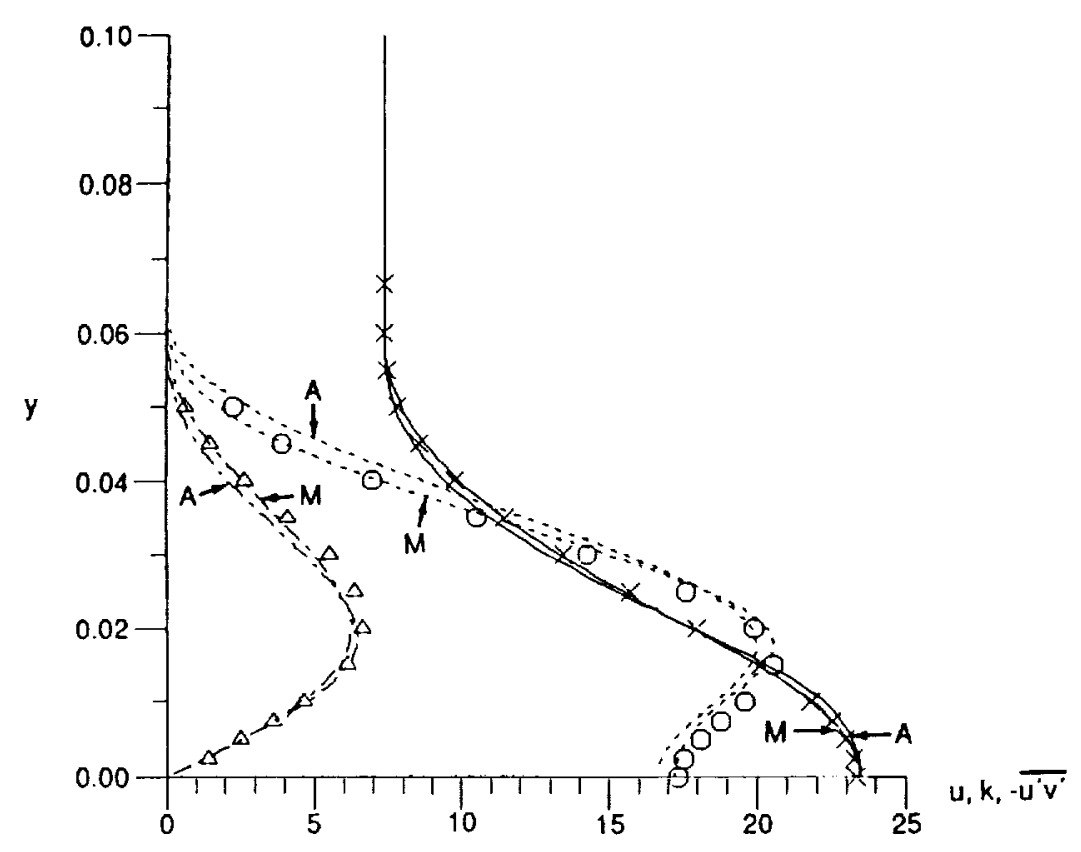

-,$\cdots \cdot-\cdots$ : COMPUT. RESULTS FOR VELOCITY, TURBULENT KINETIC

ENERGY, AND REYNOLDS STRESS, $x, 0, \Delta$ : EXP'T DATA FOR VELOCITY, TURBULENT KINETIC ENERGY, AND REYNOLDS STRESS, M: MULTIPLE-TIME-SCALE TURBULENCE MODEL,

A: ALGEBRAIC STRESS TURBULENCE MODEL.

(b) Velocity, turbulent kinetic energy and Reynolds stress at $\mathrm{x}=0.381 \mathrm{~m}$.

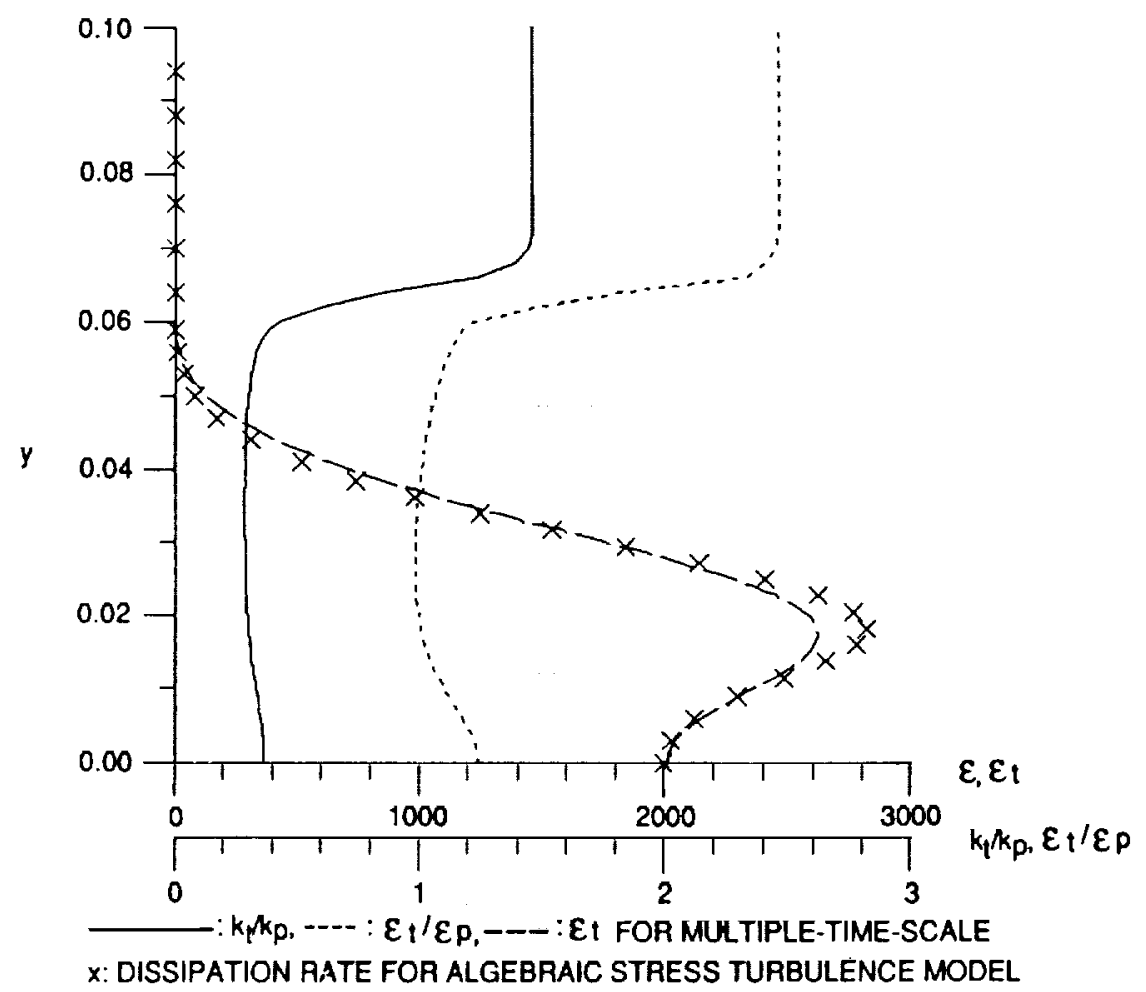

(c) Dissipation rate, $\mathrm{k}_{\mathrm{t}} / \mathrm{k}_{\mathrm{p}}$, and $\varepsilon_{\mathrm{t}} / \varepsilon_{\mathrm{p}}$ at $\mathrm{x}=0.381 \mathrm{~m}$.

Figure 3. (Continued) 


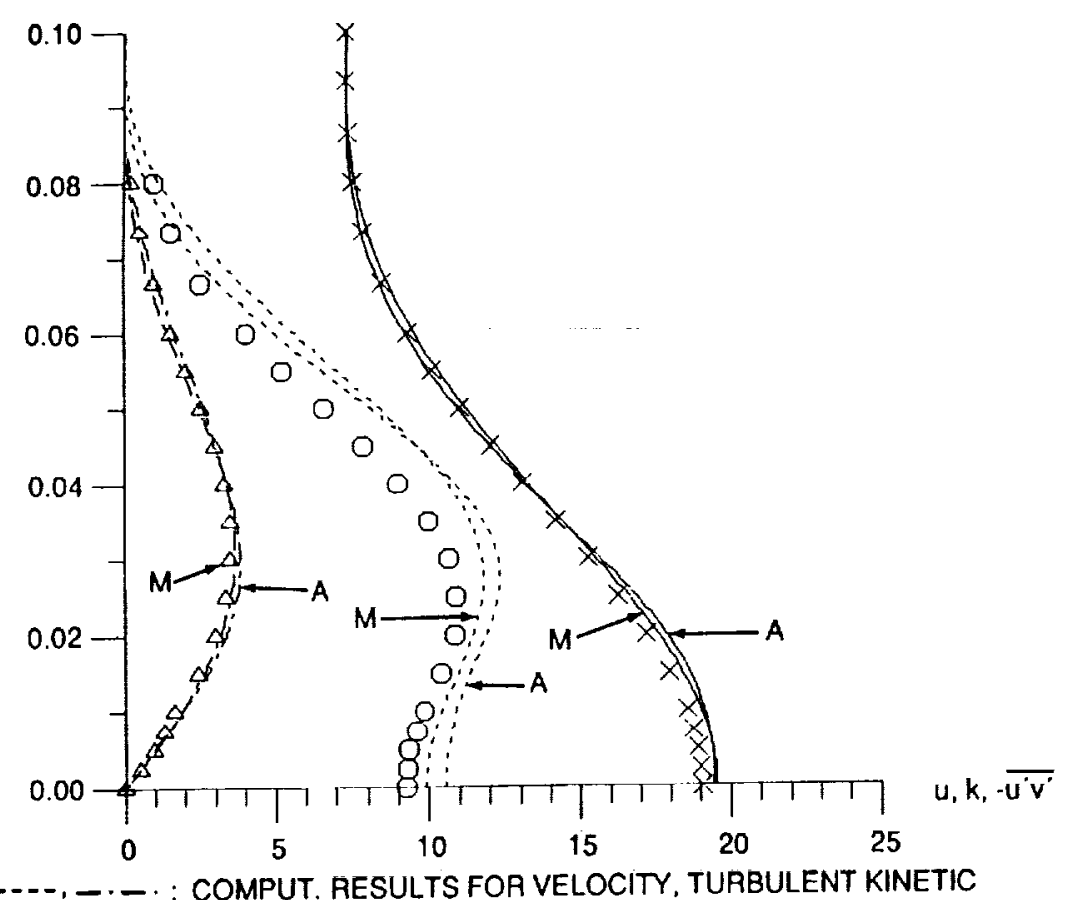

ENERGY, AND REYNOLDS STRESS, $x, 0, \Delta$ : EXP'T DATA FOR VELOCITY, TURBULENT KINETIC ENERGY, AND REYNOLDS STRESS, M: MULTIPLE-TIME-SCALE TURBULENCE MODEL,

A: ALGEBRAIC STRESS TURBULENCE MODEL.

(d) Velocity, turbulent kinetic energy, and Reynolds stress at $\mathrm{x}=0.650 \mathrm{~m}$.

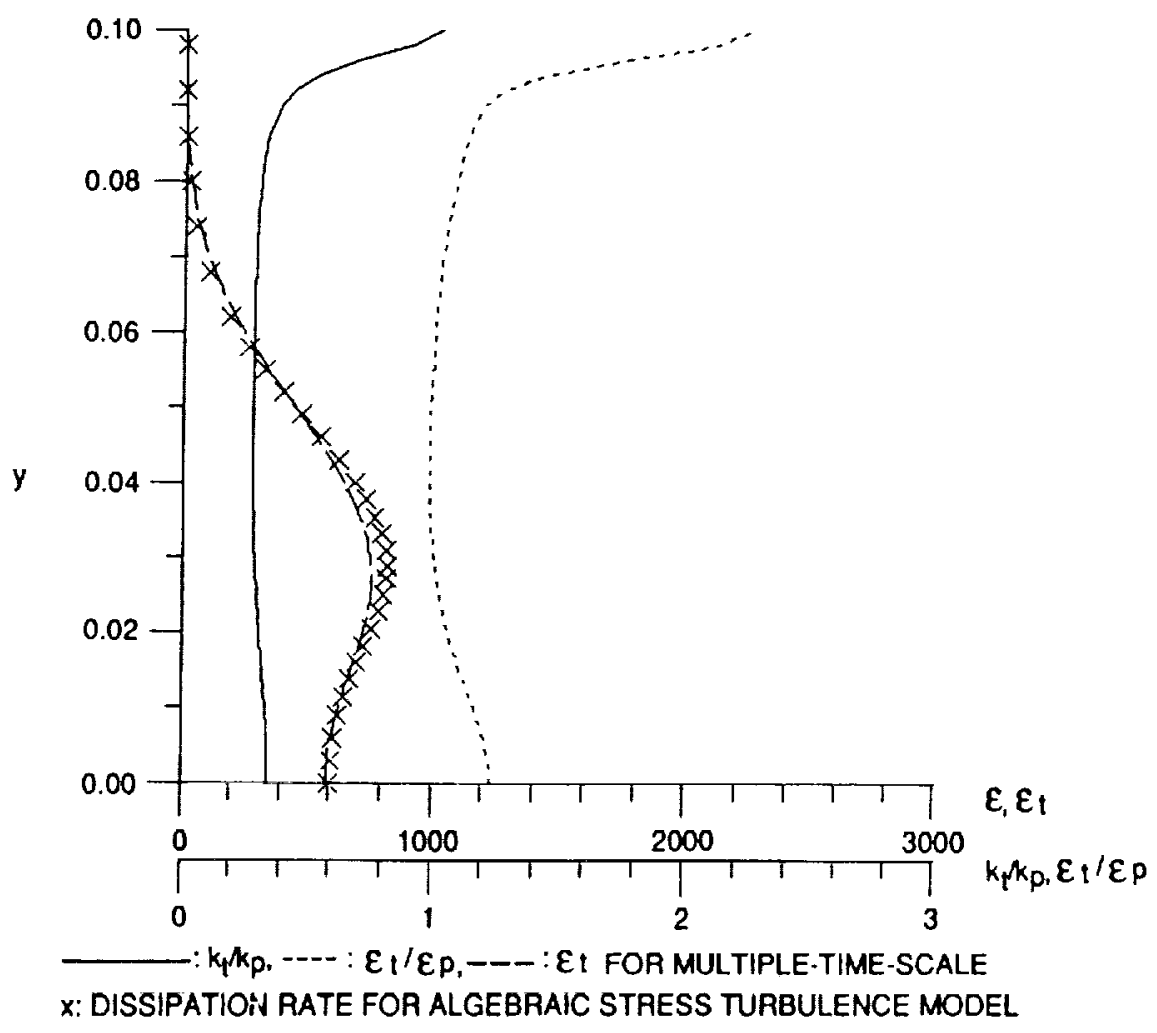

(e) Dissipation rate, $k_{t} / k_{p}$, and $\varepsilon_{t} / \varepsilon_{p}$ at $x=0.650 \mathrm{~m}$.

Figure 3. (Concluded). 


\section{3-3. A Wall Jet Issuing into a Moving Stream}

One of the most complete experimental data for the wall jet flows can be found in Irwin [16], and a finite difference computation of wall jet flows can be found in Ljuboja and Rodi [17], among many others.

Input data used in computation of the flow were obtained directly and/or by curve-fitting the experimental data [5-6]. The computational domain extended from $\mathrm{y}=0.002 \mathrm{~m}$ to $\mathrm{y}=0.08 \mathrm{~m}$ in the transverse direction; and from $\mathrm{x}=0.5532 \mathrm{~m}(\mathrm{x} / \mathrm{b}=$ $82.2)$ to $x=1.6892 \mathrm{~m}(\mathrm{x} / \mathrm{b}=251)$ in the flow direction. The transverse domain was discretized by 45 unequally spaced quadratic elements, and the flow direction domain was discretized by 1135 line-steps. An average of 12 iterations were required for each line-step to achieve the same convergence criterion given previously.

The computational results of the flow development along the downstream direction obtained by using the multiple-time-scale turbulence model are compared with that of the algebraic stress turbulence model as well as experimental data in Figure $4(a)$. It was found that the present turbulence model yielded significantly improved computational results compared with those of Reference 17 . The velocity, turbulent kinetic energy, and Reynolds stress at the two downstream locations are shown in Figures $4(\mathrm{~b})$ and $4(\mathrm{~d})$. The dissipation rates obtained by using the two turbulence models were found to be almost identical for the wall jet flow; and the ratio of $\varepsilon_{t} / \varepsilon_{p}$ exhibited sharp transition in the viscous super layer [see Figures 4(c) and 4(e)]. Both of the turbulence models yielded almost identical computational results for the wall-jet flow; nevertheless, the multiple-time-scale turbulence model yielded slightly better computational results in the outer edge of the boundary layer.

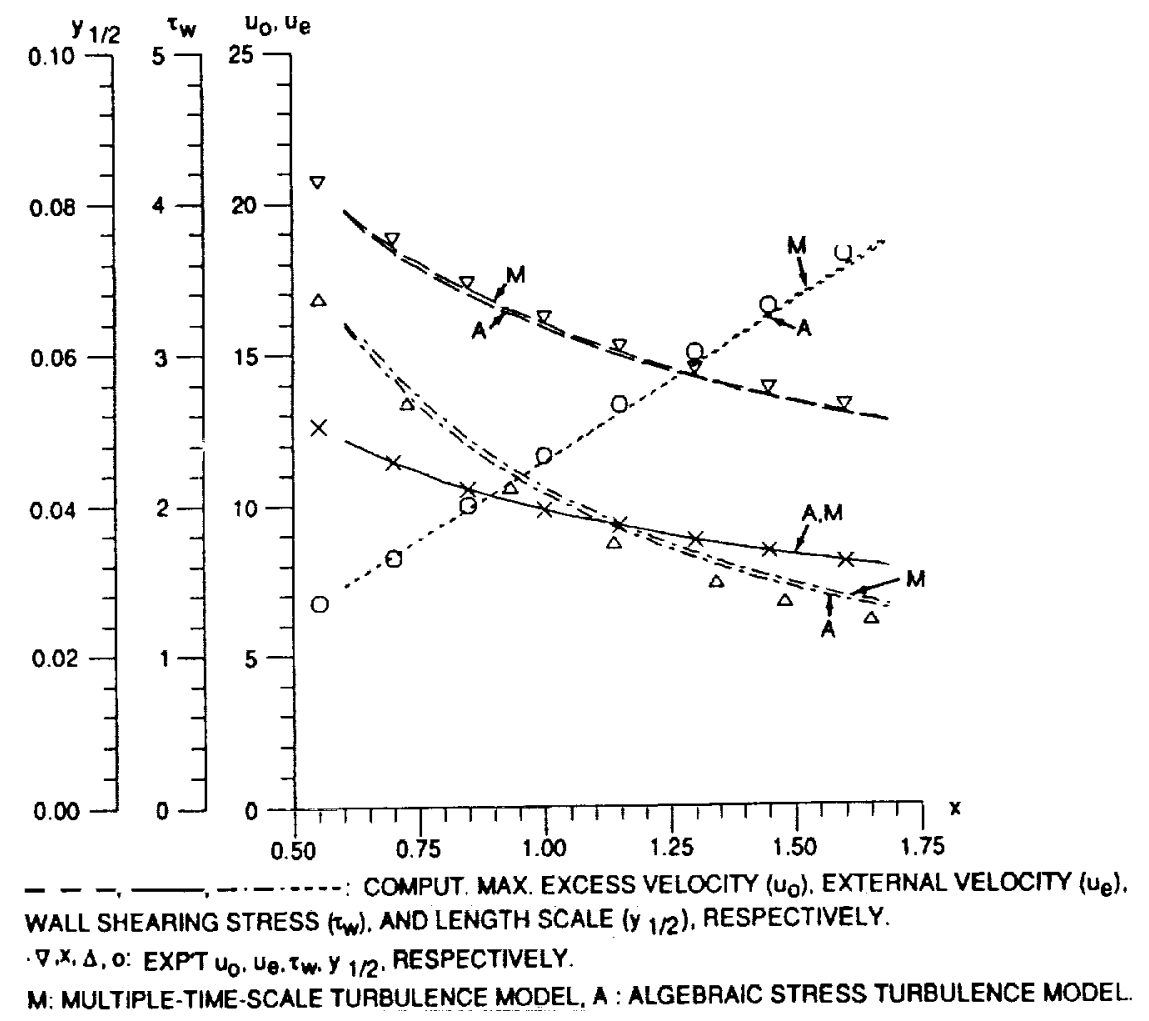

(a) Development of the wall-jet flow along the flow direction.

Figure 4. A wall-jet flow. 


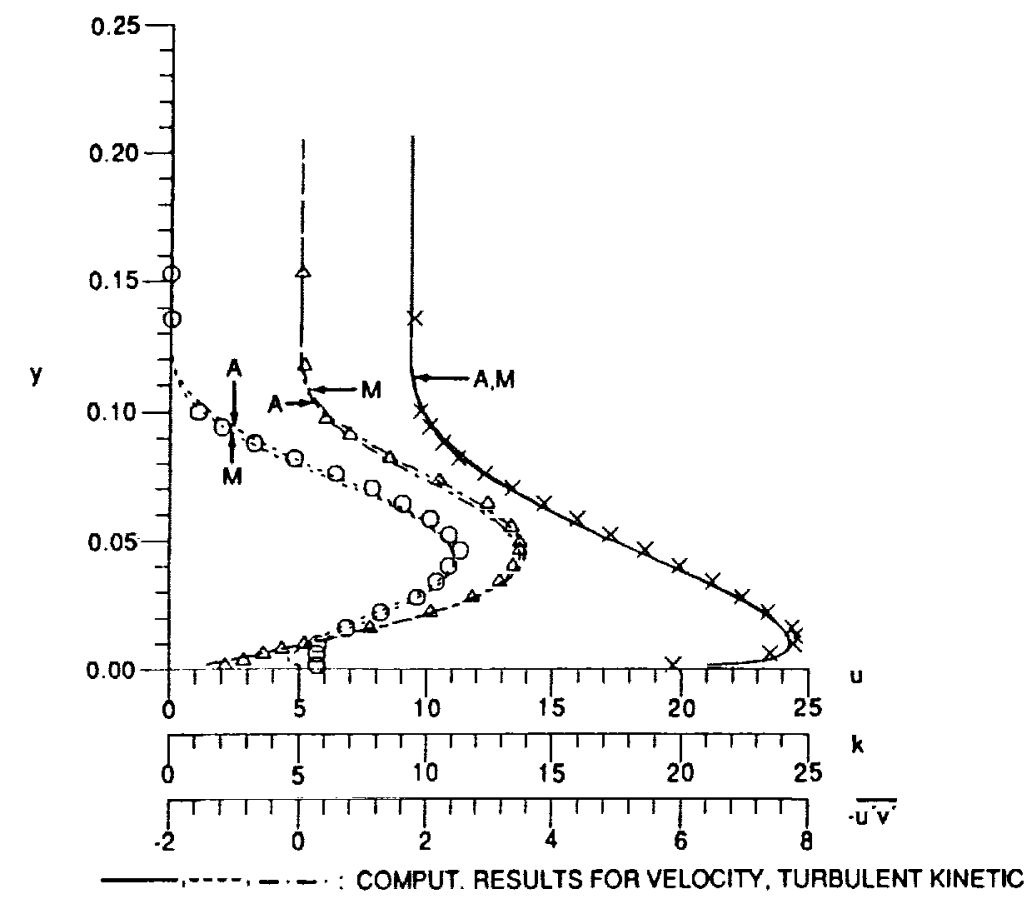

ENERGY, AND REYNOLOS STRESS, $x, 0, \Delta$ : EXP'T DATA FOR VELOCITY, TURBULENT KINETIC ENERGY, AND REYNOLDS STRESS, M: MULTIPLE-TIME-SCALE TURBULENCE MODEL,

A: ALGEBRAIC STRESS TURBULENCE MODEL.

(b) Velocity, turbulent kinetic energy, and Reynolds stress at $\mathrm{x}=1.1532 \mathrm{~m}$.

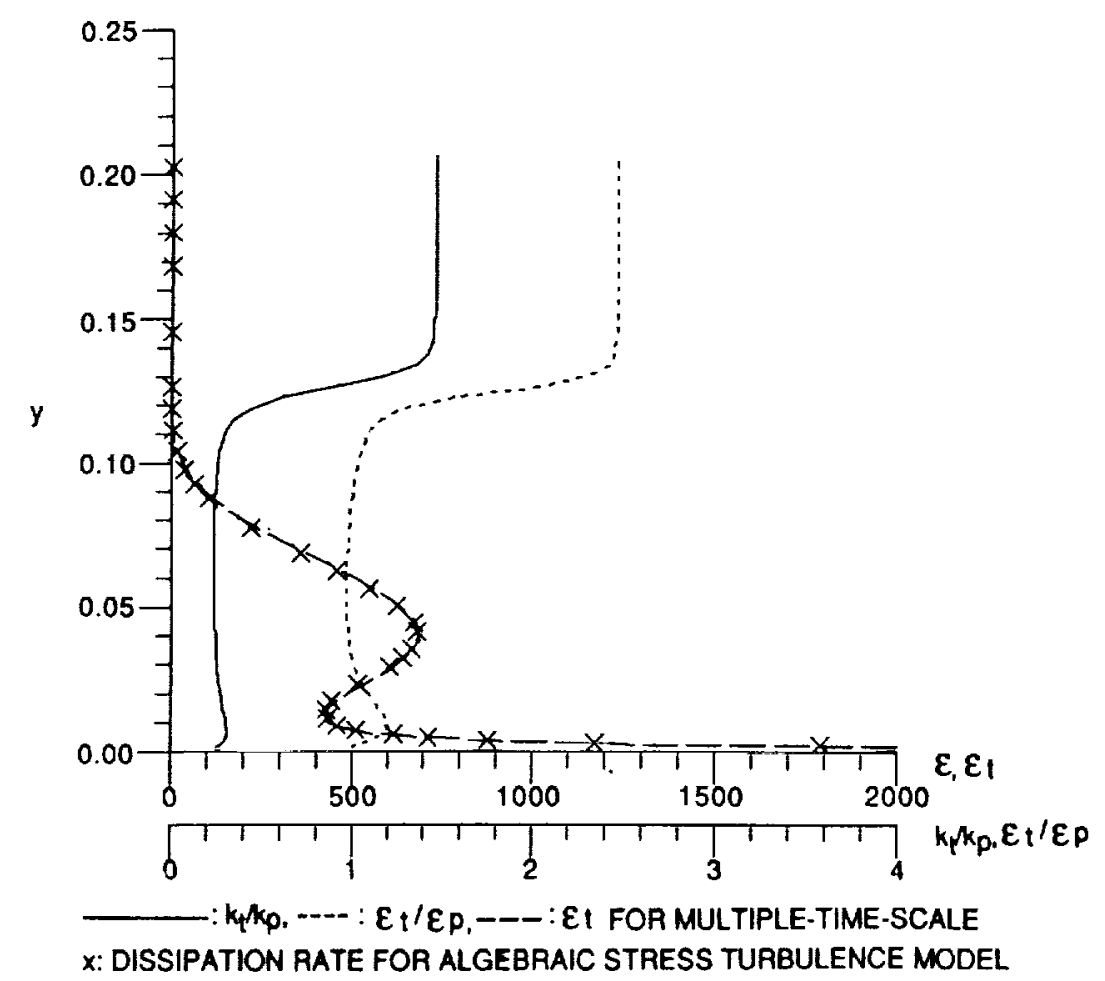

(c) Dissipation rate, $\mathrm{k}_{\mathrm{t}} / \mathrm{k}_{\mathrm{p}}$, and $\varepsilon_{\mathrm{t}} / \varepsilon_{\mathrm{p}}$ at $\mathrm{x}=1.1532 \mathrm{~m}$.

Figure 4. (Continued). 


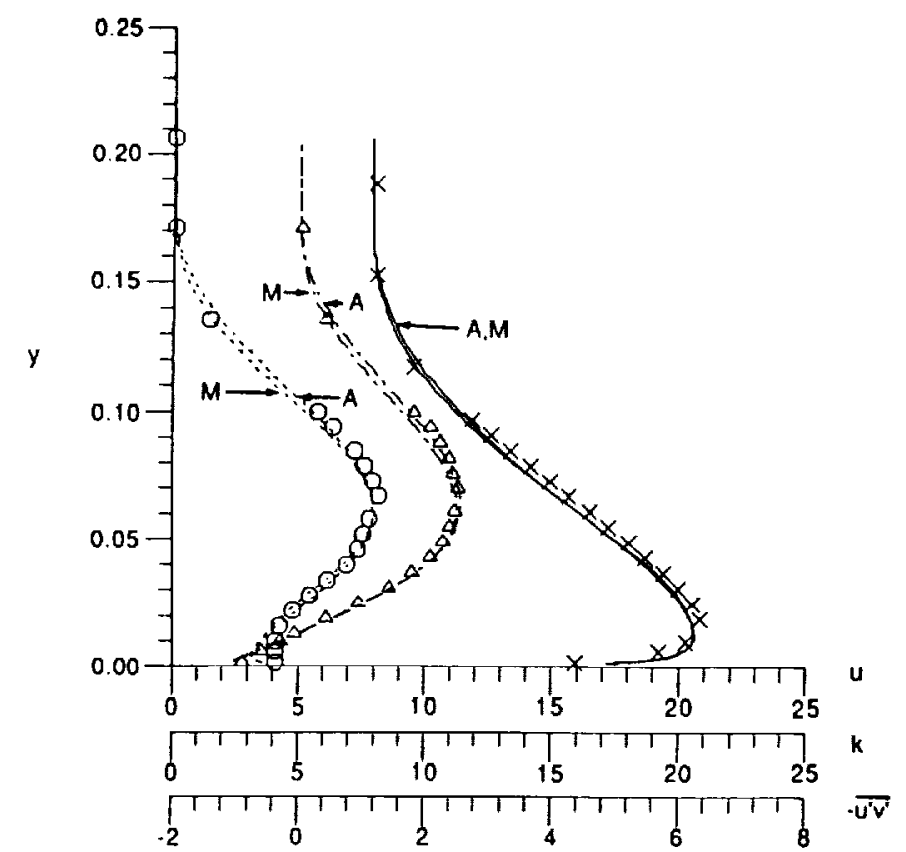

- $, \cdots,-\cdots \cdot$ : COMPUT. RESULTS FOR VELOCITY, TUABULENT KINETIC

ENERGY, AND REYNOLDS STRESS, $x, 0, \Delta$ : EXP'T DATA FOR VELOCITY, TURBULENT KINETIC ENERGY, AND REYNOLDS STRESS, M: MULTIPLE-TIME-SCALE TURBULENCE MODEL.

A: ALGEBRAIC STRESS TURBULENCE MODEL.

(d) Velocity, turbulent kinetic energy, and Reynolds stress at $x=1.6882 \mathrm{~m}$.

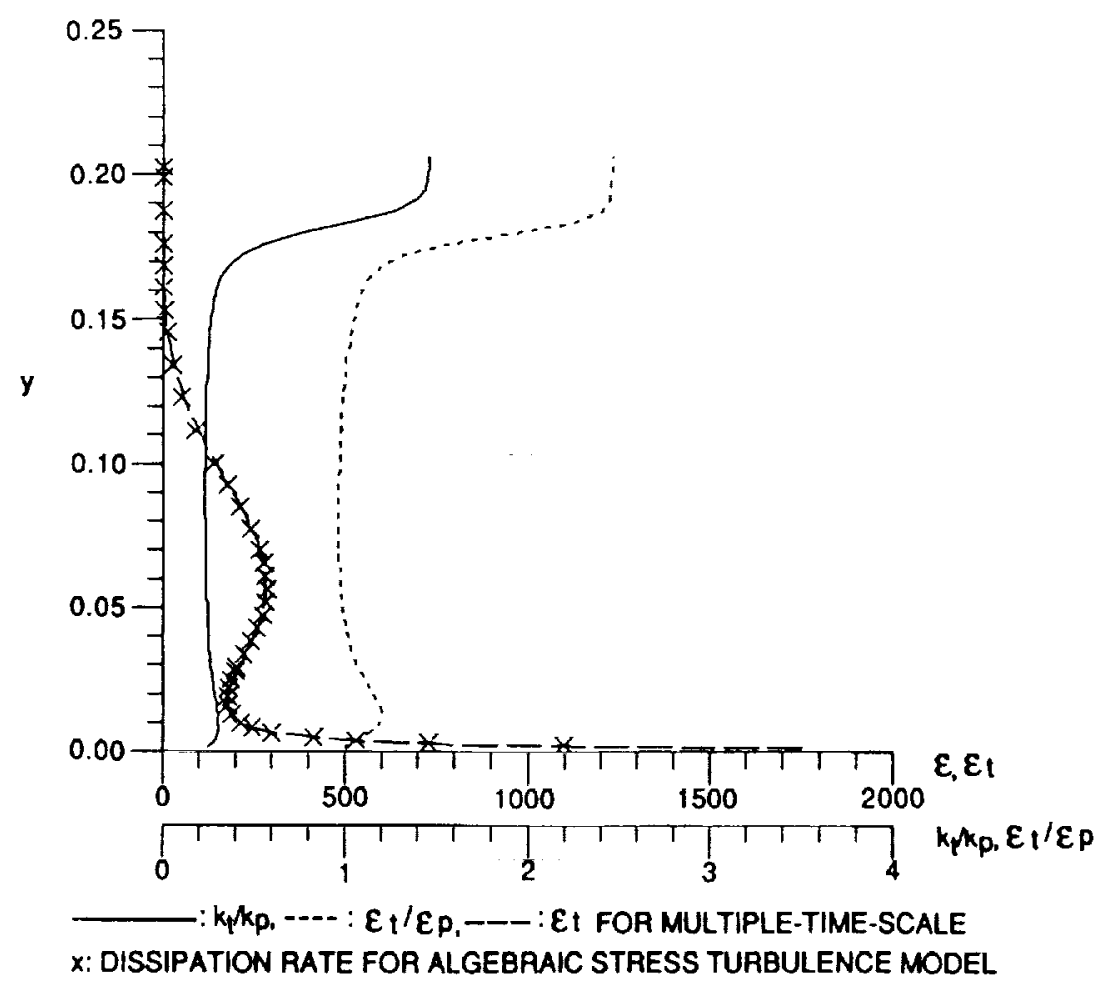

(e) Dissipation rate, $k_{t} / k_{p}$, and $\varepsilon_{t} / \varepsilon_{p}$ at $x=1.6882 \mathrm{~m}$.

Figure 4. (Concluded). 


\section{3-4. Wake-Boundary Layer Interaction Flow}

The last example case considered herein is a weakly coupled wake-boundary layer interaction flow, the experimental data of which can be found in Tsiolakis, Krause, and Muller [18]. The wake was generated by placing a cylinder inside a flat plate boundary layer flow. The free stream velocity of the boundary layer flow was $26.4 \mathrm{~m} / \mathrm{sec}$, the diameter of the cylinder was $0.01 \mathrm{~m}$, and the cylinder was separated from the wall by a distance of twice the flat plate boundary layer thickness.

The transverse domain extending from $\mathrm{y}=0.002 \mathrm{~m}$ in the near wall region up to $\mathrm{y}=0.12 \mathrm{~m}$ in the free stream region was discretized using 45 unequally spaced quadratic elements; and the flow direction domain extending from $\mathrm{x}=0.2 \mathrm{~m}(\mathrm{x} / \mathrm{d}=20)$ to $\mathrm{x}=0.86 \mathrm{~m}(\mathrm{x} / \mathrm{d}=86)$ was discretized using 825 line steps. Approximately 10 iterations were required for each line-step.

The computational results of velocity, turbulent kinetic energy, and the Reynolds stress at the two down-stream locations are shown in Figures 5(a) and 5(c). The computational results of dissipation rate, $k_{t} / k_{p}$, and $\varepsilon_{t} / \varepsilon_{p}$ are shown in Figures $5(b)$ and 5(d). Again, all of the turbulence quantities as well as the dissipation rates obtained by using the two different turbulence models were almost identical; and the ratio of $\varepsilon_{t} / \varepsilon_{p}$ showed sharp transition in the viscous super layer. It was found that the present computational results compared favorably with experimental data, in general.

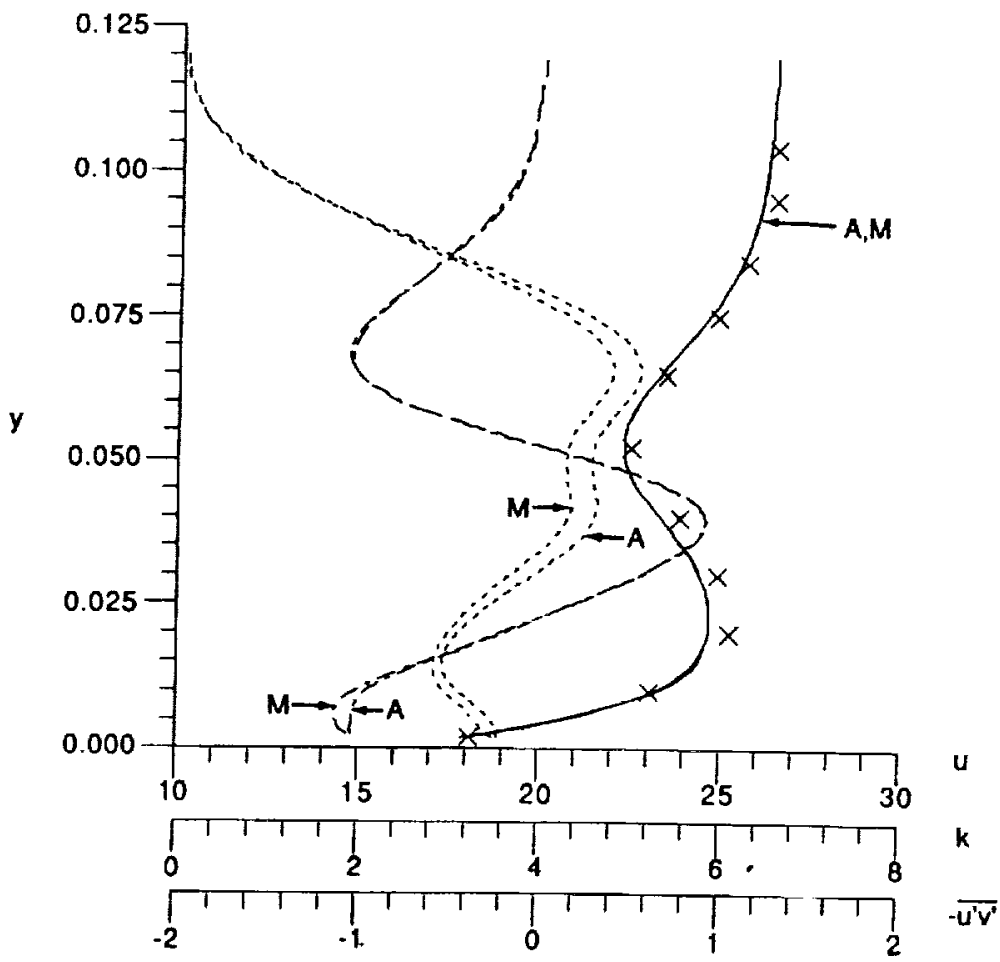

-,$\cdots \cdot-\cdots$ : COMPUT. RESULTS FOR VELOCITY, TURBULENT KINETIC ENERGY, AND REYNOLDS STRESS, $x, 0, \Delta$ : EXP'T DATA FOR VELOCITY. TURBULENT KINETIC ENERGY, AND REYNOLDS STRESS, M: MULTIPLE-TIME-SCALE TURBULENCE MODEL, A: ALGEBRAIC STRESS TURBULENCE MODEL.

(a) Velocity, turbulent kinetic energy, and Reynolds stress at $\mathrm{x}=0.40 \mathrm{~m}$.

Figure 5. A wake-boundary layer interaction flow. 


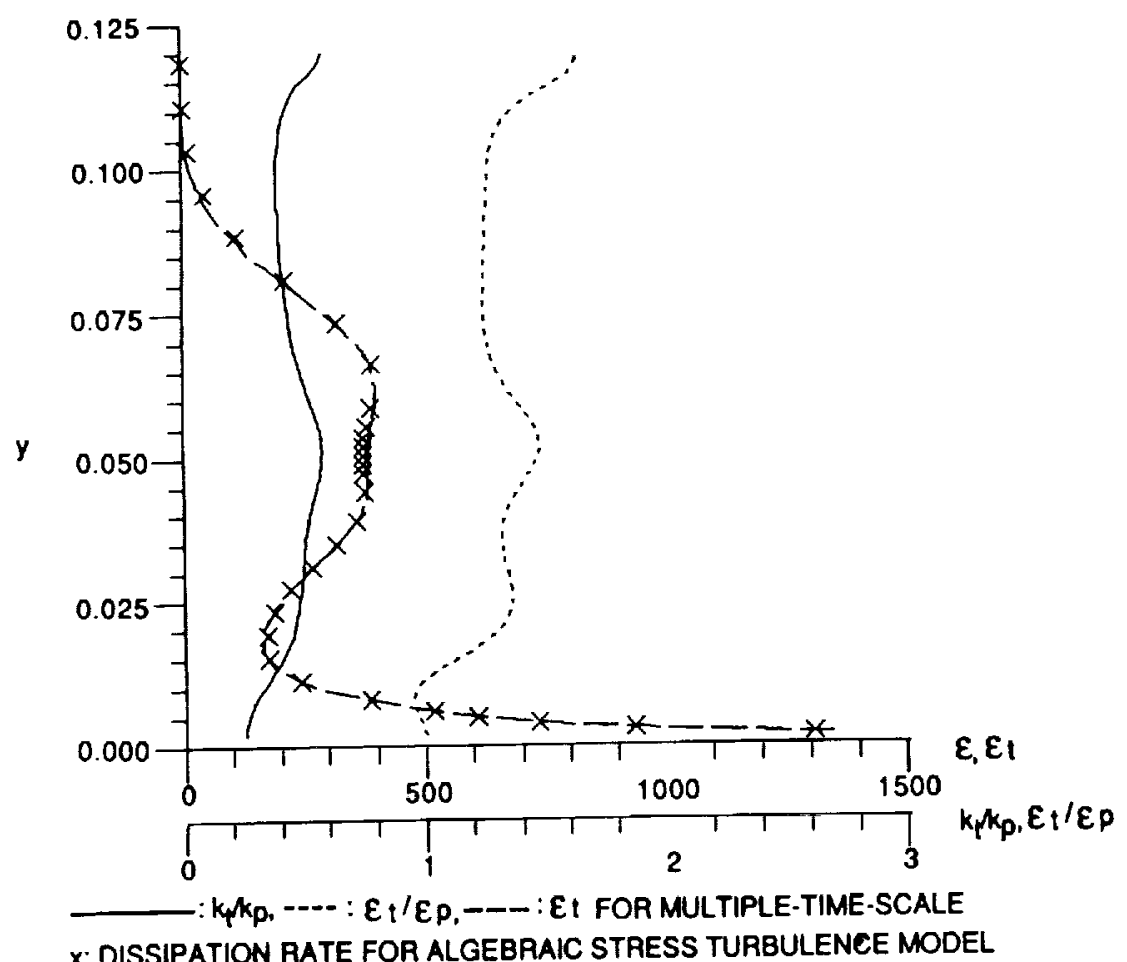

(b) Dissipation rate, $k_{t} / k_{p}$, and $\varepsilon_{t} / \varepsilon_{p}$ at $x=0.40 \mathrm{~m}$.

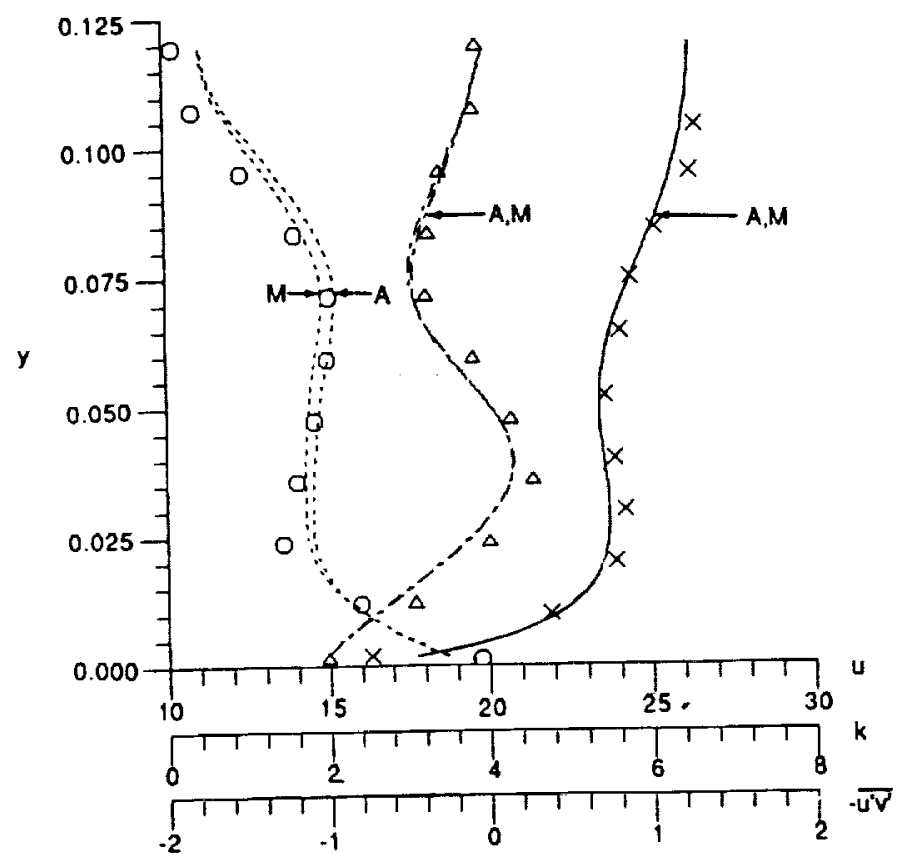

_....... - : : COMPUT. RESULTS FOR VELOCITY. TURBULENT KINETK ENERGY, AND REYNOLDS STRESS, $x, 0, \Delta$ : EXPT DATA FOR VELOCITY, TURBULENT KINETIC ENERGY, AND REYNOLDS STRESS, M: MULTIPLE-TIME-SCALE TURBULENCE MODEL, A: ALGEBRAIC STRESS TURBULENCE MODEL

(c) Velocity, turbulent kinetic energy, and Reynolds stress at $x=0.86 \mathrm{~m}$.

Figure 5. (Continued). 


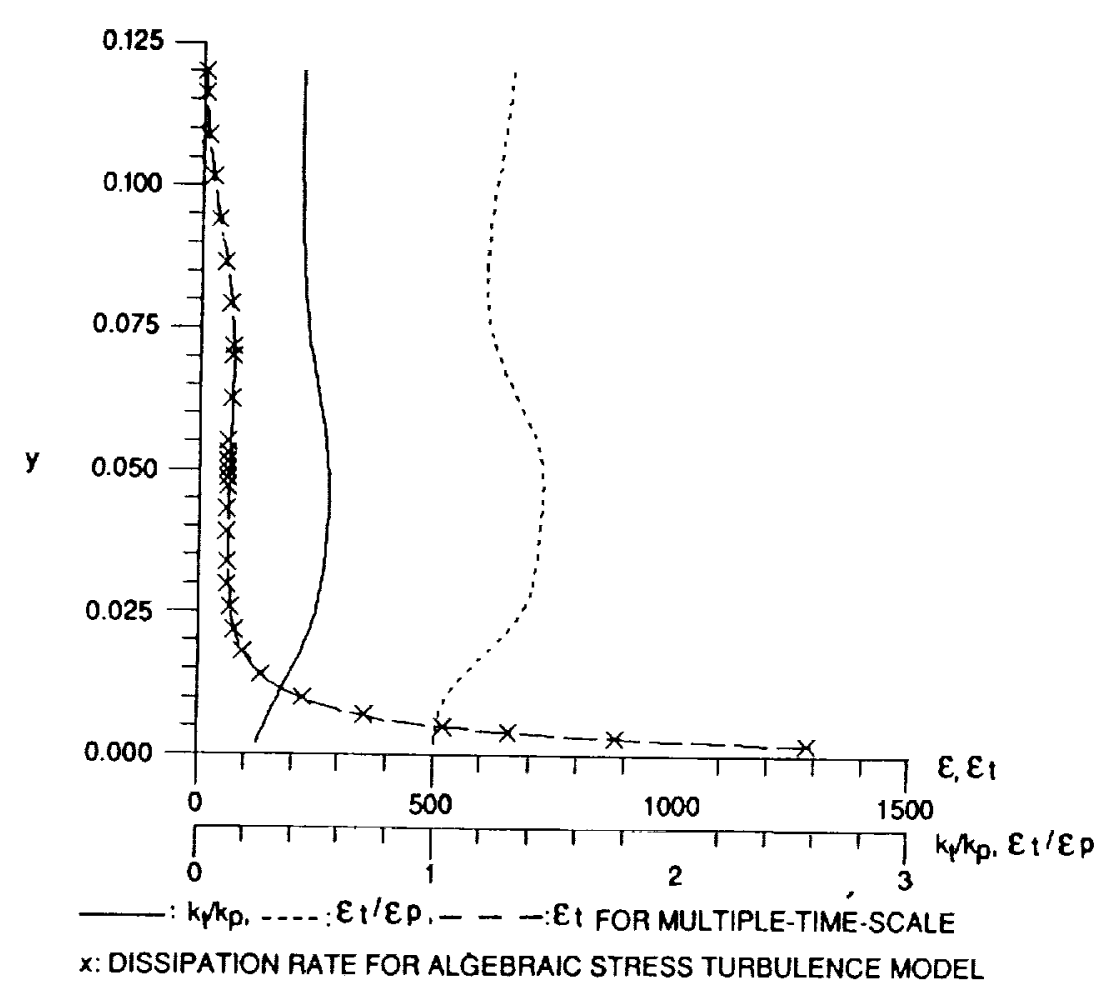

(d) Dissipation rate, $\mathrm{k}_{\mathrm{t}} / \mathrm{k}_{\mathrm{p}}$, and $\varepsilon_{\mathrm{t}} / \varepsilon_{\mathrm{p}}$ at $\mathrm{x}=0.86 \mathrm{~m}$.

Figure 5. (Concluded).

\section{CONCLUSIONS AND DISCUSSION}

A set of accurate computational results for complex turbulent boundary layer flows, i.e., the wall-jet and wake-boundary layer interaction flows, has been presented in this paper. The success may be due to the turbulence models used as well as the accurate numerical method which is free of numerical diffusion.

It was observed that the multiple-time-scale turbulence model could resolve details of the complex turbulent boundary layer flows somewhat better than the algebraic stress turbulence model. Nevertheless, both of the turbulence models yielded equivalently accurate computational results for most of the example cases considered, and could resolve the viscous super layer. In this sence, it would be appropriate to discuss the relative advantages and disadvantages of the two turbulence models.

The advantage of the multiple-time-scale turbulence model lies in its capability to model the cascade process of turbulent kinetic energy, its capability to include the variation of the effective eddy viscosity coefficient implicitly, and its potential to include more experimental observations in the future.

The disadvantages of the multiple-time-scale turbulence model over the algebraic stress turbulence model may seem to be the computational overload to solve two more transport equations. But the overload was compensated for by lack of the necessity to compute the complicated effective eddy viscosity coefficient $\left(c_{\mu}\right)$ equation used in the algebraic stress turbulence model. 


\section{APPENDIX I}

\section{THE TURBULENCE MODEL CONSTANTS}

Establishment of the turbulence model constants is based on the assumption that the ratios of $\mathrm{k}_{\mathrm{t}} / \mathrm{k}_{\mathrm{p}}$ and $\mathrm{Dk} \mathrm{k}_{\mathrm{t}} / \mathrm{Dk} \mathrm{p}$ will asymptotically approach constant values in simple homogeneous turbulent flows such as the decay of grid turbulence [19], a nearly homogeneous shear flow [20], and the near wall equilibrium turbulent flows. This assumption is justified by the computational results posterily. The model constants also need to satisfy the realizability conditions (i.e., both of the turbulent kinetic energies, energy transfer rate, and the dissipation rate cannot become negative) described below.

\section{A-1-1. Free Stream Turbulence}

The velocity gradient and the production of turbulent kinetic energy vanish in the free stream region of turbulent boundary layer flows, and the turbulence equations can be simplified as:

$$
\begin{aligned}
& \frac{D k_{p}}{D t}=-\varepsilon_{p} \\
& \frac{D \varepsilon_{p}}{\overline{D t}}=-c_{p 3} \frac{\varepsilon_{p}^{2}}{k_{p}} \\
& \frac{D k_{t}}{D t}=\varepsilon_{p}-\varepsilon_{t} \\
& \frac{D \varepsilon_{t}}{\overline{D t}}=c_{t 1} \frac{\varepsilon_{p}}{k_{t}}+c_{t 2} \frac{\varepsilon_{p} \varepsilon_{t}}{k_{t}}-c_{t 3} \frac{\varepsilon_{t}}{k_{t}}
\end{aligned}
$$

Let the ratio of the dissipation range turbulent kinetic energy to that of the production range be:

$$
\frac{k_{t}}{k_{p}}=n=\text { constant }
$$

\footnotetext{
Then, based on the definition of the total turbulent kinetic energy, i.e., $\mathrm{k}=\mathrm{k}_{\mathrm{p}}+\mathrm{k}_{\mathrm{t}}$, it can be obtained that:
} 


$$
\begin{aligned}
& k_{p}=\frac{1}{(n+1)} k \\
& k_{t}=\frac{n}{(n+1)} k .
\end{aligned}
$$

Taking material derivative of equation (A.5) yields, after rearrangement:

$$
\frac{k_{t}}{k_{p}}=\frac{\left(D k_{t} / D t\right)}{\left(D k_{p} / D t\right)}=n \text {. }
$$

Substituting equations (A.1) and (A.3) into equation (A.6) yields:

$$
\frac{t_{t}}{\varepsilon_{p}}=n+1
$$

It can be seen from equation (A.7) that the ratio of the dissipation rate to transfer rate also becomes a constant in the free stream region. Substituting equations (A.6) and (A.9) into equations (A.1) and (A.2), respectively, and dividing the results yield:

$$
\frac{\mathrm{Dk}}{\mathrm{D} \varepsilon_{\mathrm{t}}}=\frac{1}{\mathrm{c}_{\mathrm{p} 3}} \frac{\mathrm{k}}{\varepsilon_{\mathrm{t}}}
$$

where the value of $c_{p 3}$ is the decay rate of grid turbulence, and is given as, from the experimental data [19]:

$$
{ }_{\mathrm{p} 3}=1.8 \text { through } 1.92
$$

Substituting equations (A.7) and (A.9) into equations (A.3) and (A.4) and dividing the results yields:

$$
\frac{\mathrm{Dk}}{\mathrm{D} \varepsilon_{\mathrm{t}}}=\frac{-1}{\mathrm{~d}_{\mathrm{gt}}} \frac{\mathrm{k}}{\varepsilon_{\mathrm{t}}}
$$

where $d_{g t}=c_{t 1} / n /(n+1)+c_{t 2} / n-(n+1) c_{t 3} / n$ is the decay rate of the grid turbulence, and hence: 


$$
\frac{c_{t 1}}{n(n+1)}+\frac{c_{t 2}}{n}-\frac{(n+1) c_{t 3}}{n}=-c_{p 3} \text {. }
$$

In the free stream region, the eddy viscosity equation can be written as:

$$
v_{t}=c_{\mu f} \frac{k^{2}}{\varepsilon_{p}}=c_{\mu f}(n+1) \frac{k^{2}}{\varepsilon_{t}},
$$

where the constant $(n+1)$ plays the role of the $c_{\mu}$ function in the algebraic stress turbulence model, and the constant $n$ can be determined from experimental data or from the $c_{\mu}$ function of the algebraic stress turbulence model.

\section{A-1-2. Near Wall Equilibrium Flow}

In the near wall region, where the turbulence is in equilibrium (the production rate is approximately equal to the dissipation rate), it can be assumed that:

$$
\operatorname{Pr}=\varepsilon_{\mathrm{p}}=\varepsilon_{\mathrm{t}}
$$

As in the standard wall function analysis [13], it is assumed that the convective transport of turbulence quantities is negligible compared with the diffusive transport, and that both of the turbulent kinetic energies are almost constant in the near wall region. Then the turbulence equations can be simplified as:

$$
\begin{aligned}
& \frac{d}{d y}\left[\left(\nu+\frac{\nu_{t}}{\sigma_{k p}}\right) \frac{\partial k_{p}}{\partial y}\right]=0 \\
& \frac{d}{d y}\left[\left(\nu+\frac{\nu_{t}}{\sigma_{\varepsilon p}}\right) \frac{\partial \varepsilon_{p}}{d y}\right]=\frac{\varepsilon_{p}}{k_{p}}\left(c_{p 1}+c_{p 2}-c_{p 3}\right) \\
& \frac{d}{d y}\left[\left(\nu+\frac{\nu_{t}}{\sigma_{k t}}\right) \frac{\partial k t}{d y}\right]=0 \\
& \frac{d}{d y}\left[\left(\nu+\frac{\nu_{t}}{\sigma_{\varepsilon t}}\right) \frac{\partial \varepsilon_{t}}{d y}\right]=\frac{\varepsilon_{p}}{k t}\left(c_{t 1}+c_{t 2}-c_{t 3}\right)
\end{aligned}
$$

From the mixing length assumption, it can be obtained that: 


$$
\begin{aligned}
& \varepsilon=\frac{c_{\mu}^{3 / 4} k^{3 / 2}}{k y}=\frac{c_{\mu}^{3 / 4}\left(k_{p}+k_{t}\right)^{3 / 2}}{\kappa y} \\
& v_{t}=c_{\mu} \frac{k^{2}}{\varepsilon}=c_{\mu} \frac{\left(k_{p}+k_{t}\right)^{2}}{\varepsilon_{p}}
\end{aligned}
$$

where $\varepsilon\left(\varepsilon=\varepsilon_{p}=\varepsilon_{t}\right)$ is the dissipation rate in the near wall region. Substituting equations (A.20) and (A.21) into equation (A.17) yields:

$$
\frac{\mathrm{k}_{\mathrm{t}}}{\mathrm{k}_{\mathrm{p}}}=\frac{\mathrm{k}^{2}}{\sigma_{\varepsilon p} c_{\mu}^{1 / 2}\left(c_{p 3}-c_{p 1}-c_{p 2}\right)}-1
$$
yields:

In the same way, substituting equations (A.20) and (A.21) into equation (A.19)

$$
\frac{k_{t}}{k_{p}}=\frac{k^{2}}{\sigma_{E t} c_{\mu}^{1 / 2}\left(c_{t 3}-c_{t 1}-c_{t 2}\right)}-1 \text {. }
$$

The ratio of the turbulent kinetic energies, $\mathrm{k}_{\mathrm{t}} / \mathrm{k}_{\mathrm{p}}$, obtained from the energy transfer equation and the dissipation equation should be the same in the near wall region. Equating equations (A.22) and (A.24) yields:

$$
\sigma_{\varepsilon p}\left(c_{p 3}-c_{p 1}-c_{p 2}\right)=\sigma_{\varepsilon t}\left(c_{t 3}-c_{t 1}-c_{t 2}\right)
$$

Equations (A.22) and (A.23) provide two constraint conditions for the turbulence model constants to satisfy, since neither of the turbulent kinetic energies can become negative.

\section{A-1-3. Homogeneous Turbulent Shear Flow}

The homogeneous turbulent shear flow experiment due to Harris et al. [20] is considered in the following. In the experiment, the turbulent flow with constant mean velocity gradient approached asymptotic state in which scales and turbulent kinetic energy grow monotonically. The experimental data at the downstream end of the test section are given as $\varepsilon_{\mathrm{t}}=3.35 \mathrm{~m}^{2} / \mathrm{sec}^{3}, \mathrm{k}=\mathrm{k}_{\mathrm{p}}+\mathrm{k}_{\mathrm{t}}=0.41 \mathrm{~m}^{2} / \mathrm{sec}^{2}$, and $\operatorname{Pr}=5.84$ $\mathrm{m}^{3} / \mathrm{sec}^{2}$, where the production rate has been estimated using the relationship that $\operatorname{Pr}=\overline{-u^{\prime} v^{\prime}}(\partial u / \partial y)$. For the turbulent flow with constant mean velocity gradient, 
the production range turbulence equations, equations ( 3 ) and (5), can be written as:

$$
\begin{aligned}
& \frac{D k_{p}}{D t}=\operatorname{Pr}-\varepsilon_{p} \\
& \frac{D \varepsilon_{p}}{D t}=c_{p 1} \frac{\operatorname{Pr}^{2}}{k_{p}}+c_{p 2} \frac{\operatorname{Pr} \varepsilon_{p}}{k_{p}}-c_{p 3} \frac{\varepsilon_{p}}{k_{p}},
\end{aligned}
$$

and the dissipation range turbulence equations can be written as:

$$
\begin{aligned}
& \frac{D k_{t}}{\bar{D} t}=\varepsilon_{p}-\varepsilon_{t} \\
& \frac{D \varepsilon_{t}}{\overline{D t}}=c_{t 1} \frac{\varepsilon_{p}}{k_{t}}+c_{t 2} \frac{\varepsilon_{p} \varepsilon_{t}}{k_{t}}-c_{t 3} \frac{\varepsilon_{t}}{k_{t}} .
\end{aligned}
$$

It is assumed that the partitioning of the turbulent kinetic energy spectrum is dependent on the ratio of production rate over dissipation rate. Let the ratios of production rate to dissipation rate and the energy transfer rate to dissipation rate be $\alpha$ and $\beta$, respectively, i.e.,

$$
\begin{aligned}
& \frac{\operatorname{Pr}}{\varepsilon_{\mathrm{t}}}=\alpha \\
& \frac{\varepsilon_{\mathrm{p}}}{\varepsilon_{\mathrm{t}}}=\beta
\end{aligned}
$$

Substituting equations (29) through (31) into equations (25) and (26) yields, after a few algebra:

$$
\frac{\varepsilon_{t}}{\mathrm{k}} \frac{\mathrm{Dk}}{\bar{D} \varepsilon_{t}}=\gamma=\frac{\beta(\alpha-\beta)}{\left(c_{p 1} \alpha^{2}+c_{p 2} 2^{\alpha \beta}-c_{p 3} \beta^{2}\right)}
$$

where the constant $\gamma$ can be obtained from the experimental data as shown below. The length scale $\ell$ is related to the dissipation rate as: 


$$
\ell=\frac{\mathrm{c}_{\mu} \mathrm{k}^{3 / 2}}{\varepsilon}
$$

Taking the derivative of equation (A.33) yields, after some rearrangement:

$$
\frac{\mathrm{d} \ell}{\ell}=\frac{3}{2} \frac{\mathrm{dk}}{\mathrm{k}}-\frac{\mathrm{d} \varepsilon}{\varepsilon}
$$

From the experimental data, we have:

$$
\frac{\mathrm{k}}{\mathrm{dk}} \frac{\mathrm{d} \ell}{\ell}=0.6818
$$

Substituting equation (A.35) into (A.34) yields:

$$
\gamma=\frac{k}{\varepsilon_{t}} \frac{\mathrm{d} \varepsilon_{t}}{d k}=0.82
$$

In the similar way, it can be obtained from equations (27) and (28) that:

$$
\frac{\varepsilon_{\mathrm{t}}}{\mathrm{k}} \quad \frac{\mathrm{dk}}{\mathrm{d} \varepsilon_{\mathrm{t}}}=\gamma=\frac{(\alpha-\beta)}{\left(c_{\mathrm{t} 1^{\beta}}{ }^{2}+c_{\mathrm{t} 2^{\beta}}-c_{\mathrm{t} 3}\right)},
$$

where the physical implication of $\gamma$ is the same in equation (A.32).

The turbulence model constants need to satisfy equations (A.10), (A.13), (A.24), (A.32), and (A.37) as well as the constraint conditions imbedded in equations (A.22) and (A.37).

The turbulence model constants given previously were obtained by assuming that the decay rate of grid turbulence $\left(c_{p 3}\right)$ is equal to 1.84 , the ratio of $k_{t} / k_{p}$ in the free stream region $(n)$ is equal to 1.5 , and the ratios of $\operatorname{Pr} / \varepsilon_{t}$ and $\varepsilon_{p} / \varepsilon_{t}$ for the homogeneous shear flow [20] are equal to 1.5 and 1.05 , respectively. The constant $c_{t 1}$ was obtained to be 0.29 through computer optimization. Note that the ratio of $\mathrm{Pr} / E_{t}$ is equal to 1.74 according to the experimental data given in Harris et al. [20]. But the ratio of $\operatorname{Pr} / \varepsilon_{t}$ is equal to 1.74 had been obtained only at the downstream end of the test section, and the data would be subjected to experimental uncertainties. As more experimental data become available, the turbulence model constants could be better determined in the future. 


\section{APPENDIX II}

\section{CONTROL-VOLUME BASED FINITE DIFFERENCE COMPUTATION OF SEPARATED AND SWIRLING TURBULENT FLOWS}

A control volume based finite difference computation of elliptic turbulent flows is presented in this Appendix. In turbulent flow computations, numerical uncertainties such as grid size, grid spacing, wall function, and numerical diffusion may mask the performance of a turbulence model. The details on the control-volume based finite difference code (TEACH-T) used herein can be found in Reference 23. The example problems considered were a backward-facing flow [22] and a confined swirling jet flow [23].

\section{A-2-1. A Turbulent Backward-Facing Step Flow}

For the backward-facing step flow case, the upstream boundary has been located at five step heights upstream of the expansion corner. Flat profiles for the flow direction velocity $\left(\mathrm{U}_{0}\right)$ of $18.5 \mathrm{~m} / \mathrm{sec}$, turbulent kinetic energy of $1.027 \mathrm{~m}^{2} / \mathrm{sec}^{2}$, and the dissipation rate of $780 \mathrm{~m}^{2} / \mathrm{sec}^{3}$, have been used as the inlet boundary conditions. The turbulent kinetic energy and the dissipation rate have been obtained using the relationships that $\mathrm{k}=0.003 \mathrm{U}_{0}^{2}$ and $\varepsilon=\mathrm{c}_{\mu \mathrm{f}} \mathrm{f}^{3 / 2} / \ell$, respectively, where $\ell$ $(=0.003 \mathrm{H})$ is the length scale [24]. The inlet boundary condition for the ratios of $\mathrm{k}_{\mathrm{t}} / \mathrm{k}_{\mathrm{p}}$ and $\varepsilon_{\mathrm{t}} / \varepsilon_{\mathrm{p}}$ have been assumed to be 0.25 and 1.0 , respectively, based on the computational result of the fully developed channel flow. The Reynolds number based on the inlet flow condition was 45,000 . The computed streamline and the turbulent kinetic energy contours, for the expansion ratios of $1: 2$, are shown in Figures A.1 and A.2, respectively. The predicted reattachment length was $6.3 \mathrm{H}$, where $H$ is the step height, which is in much closer agreement with the experimentally observed value of $7( \pm 1) \mathrm{H}$ compared with the $5.2 \mathrm{H}$ predicted by using the standard $\mathrm{k}-\varepsilon$ turbulence model [24]. The computed mean velocity profiles at three cross-stream locations $(\mathrm{x} / \mathrm{H}=5.2,10.7$, and 16$)$ are compared with experimental data in Figure A.3. The velocity profile at $\mathrm{x} / \mathrm{H}=5.2$ indicates that the recirculation zone is smaller than that of the experimental data [24]. The turbulent kinetic energy $\left(k=k_{p}+k_{t}\right)$ and the shear stress profiles at three cross-stream locations are shown in Figures A.4 and A.5, respectively. These figures illustrate that the peaks and shapes of these two turbulence quantities have been successfully predicted by the present turbulence model. It can be found in Reference 24 that the standard $\mathrm{k}-\varepsilon$ turbulence model severely under-predicted the reattachment length and the magnitudes of these turbulence quantities. It can be seen from these computational results that the multipletime-scale turbulence model can yield significantly improved predictions for separated turbulent flows than the standard $\mathrm{k}-\varepsilon$ turbulence model.

The ratios of dissipation rate to energy transfer rate at the same cross-stream locations and at $\mathrm{x} / \mathrm{H}=27$ are shown in Figure A.6. It can be seen that the ratio is smaller in the high turbulence region than in the low turbulence region. Thus, the turbulent eddy viscosity coefficient is smaller in the high turbulence region than in the low turbulence region, see equation (10). At far downstreams, i.e., $x / H \geq 27$, the flow approached fully developed channel flow state and the ratio $\left(\varepsilon_{t} / \varepsilon_{p}\right)$ became almost uniform across the channel width. 
The streamline and the turbulent kinetic energy contours obtained by using $\sigma_{\mathrm{kp}}=\sigma_{\mathrm{kt}}=1.0$ and $\sigma_{\varepsilon p}=\sigma_{\varepsilon t}=1.3$, which are the most frequently used coefficients in most of the turbulence models [24], are shown in Figures A.7 and A.8, respectively. These contour lines compare favorably with those in Figures A.1 and A.2, except that the reattachment length was slightly shorter than the previous case.

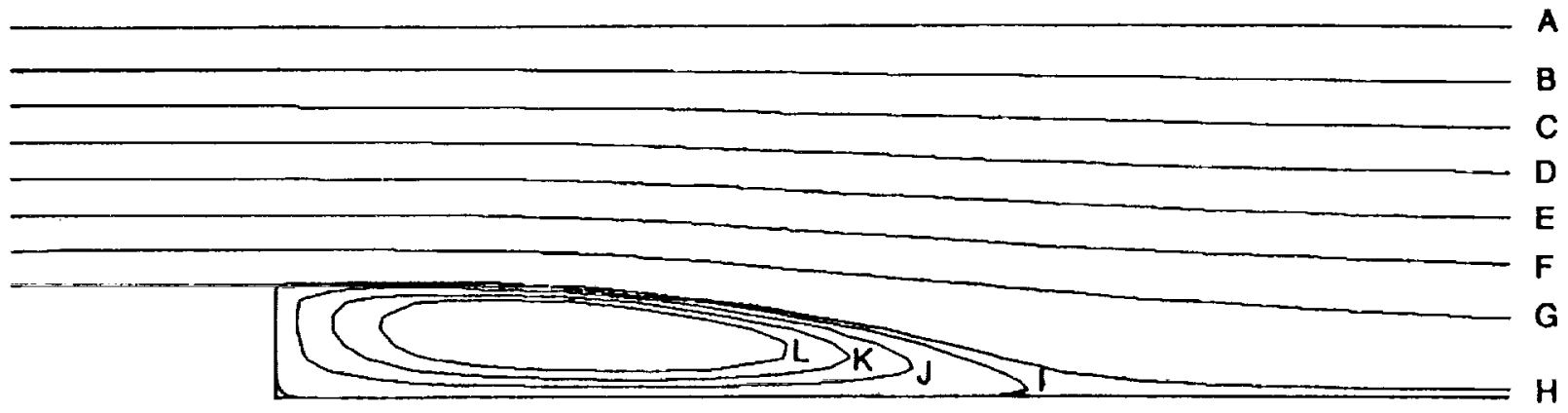

Figure A-1. Streamline contour for backward-facing step flow.

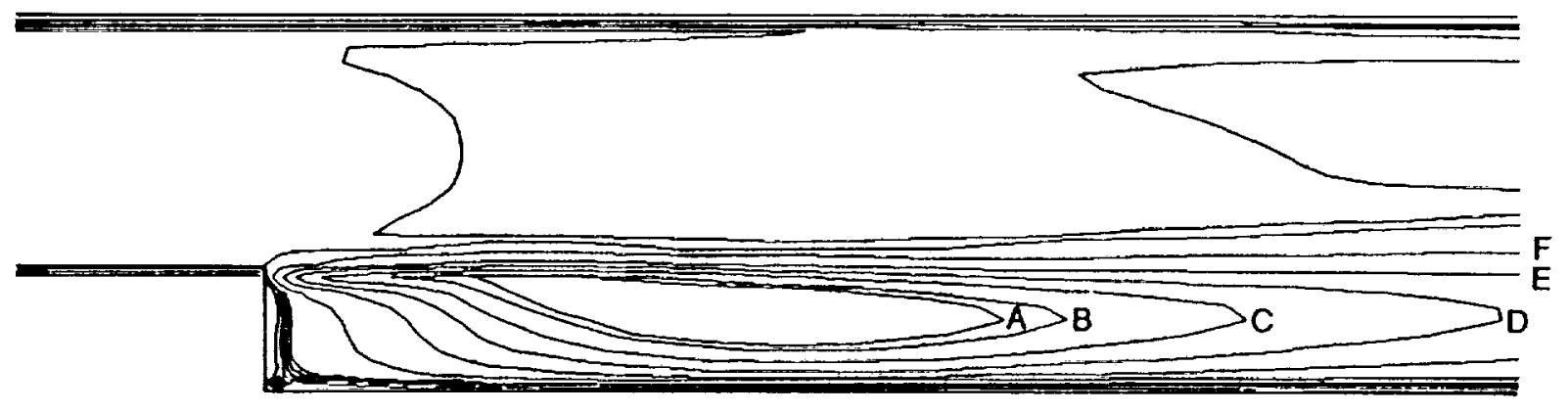

Figure A-2. Turbulent kinetic energy contour for backward-facing step flow. 


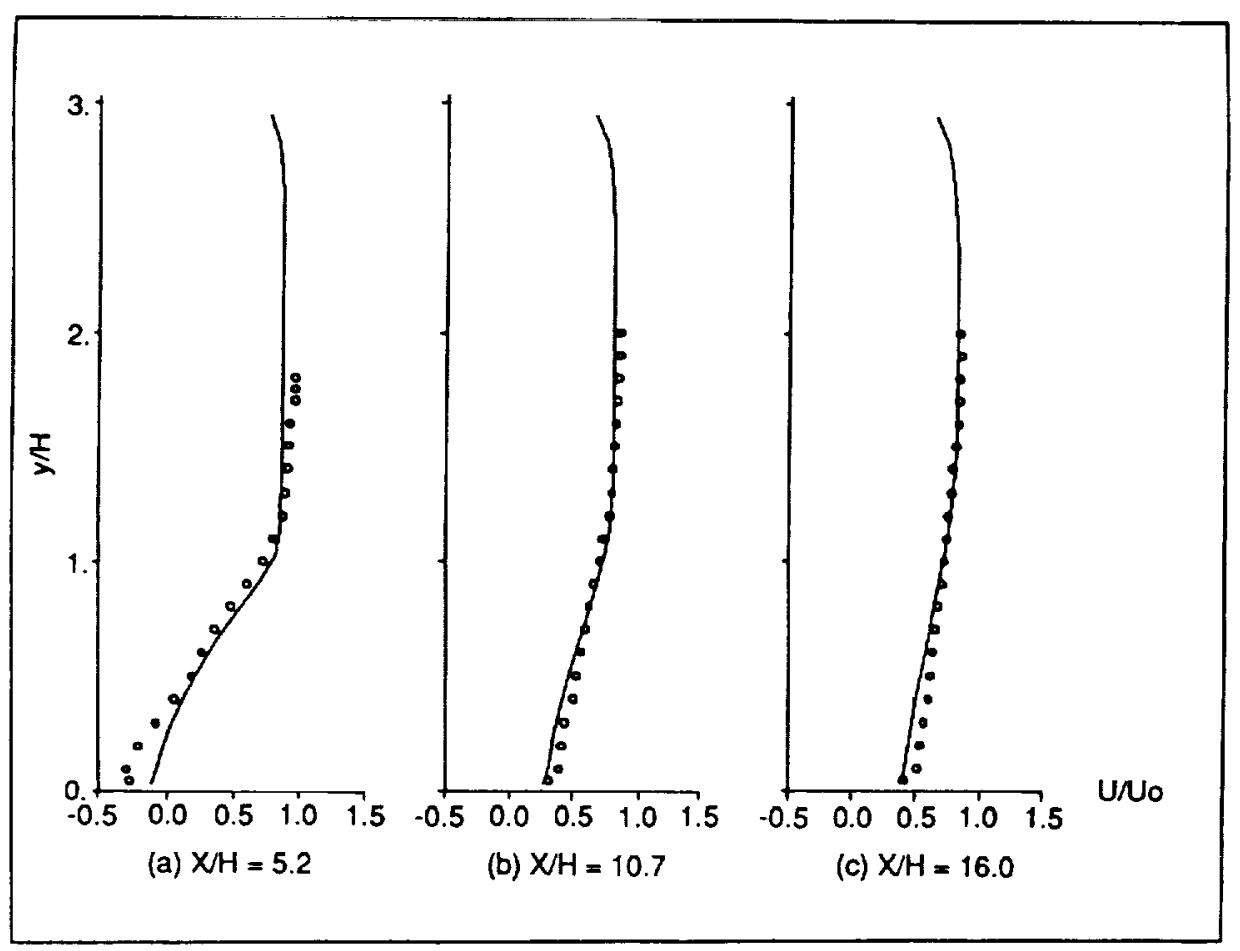

- : comput. result, o: exp't data, $\mathrm{H}$ : step height.

Figure A-3. Velocity profiles for backward-facing step flow.

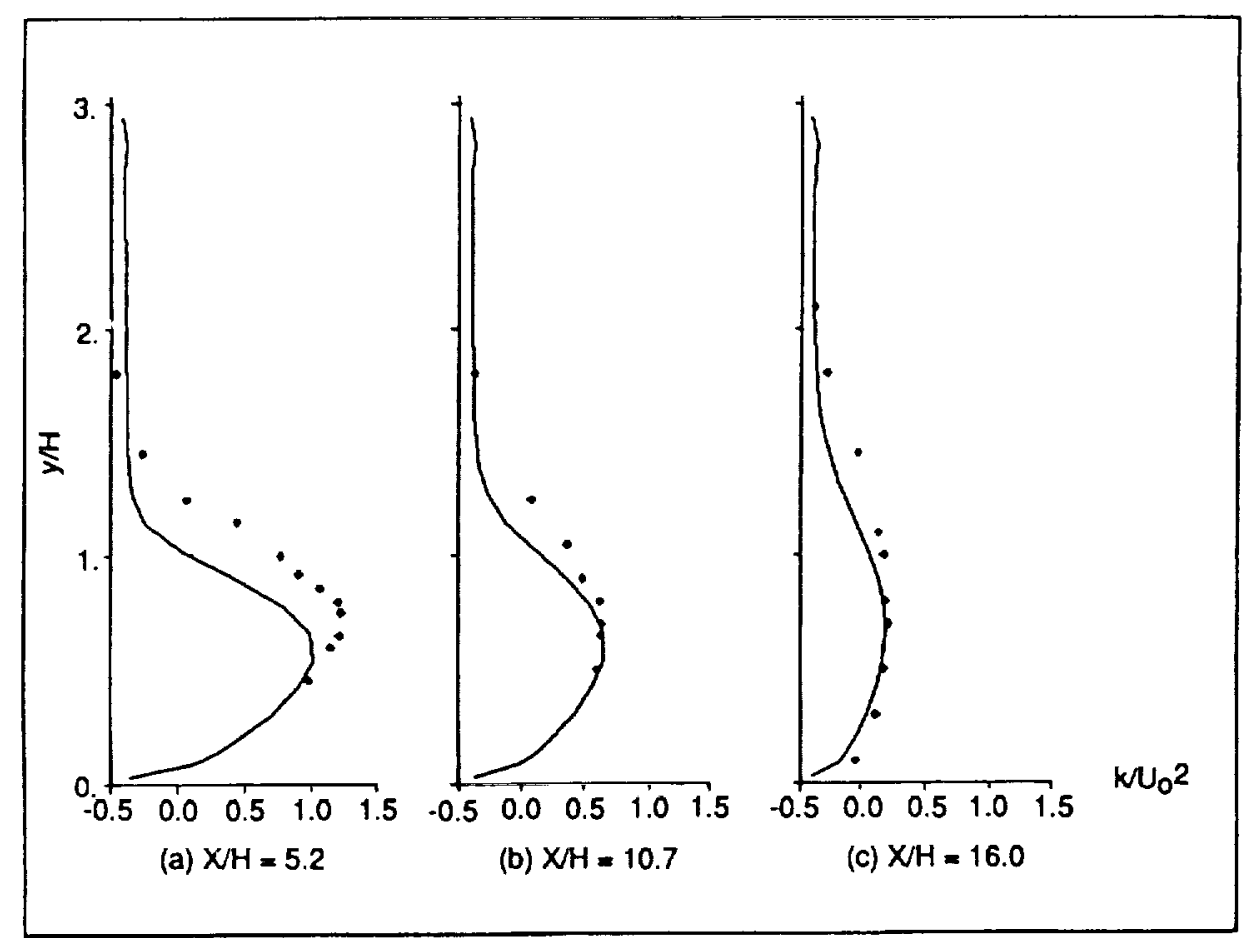

- : comput. result, $\diamond: \exp ^{\prime} t$ data.

Figure A-4. Turbulent kinetic energy profiles for backward-facing step flow. 


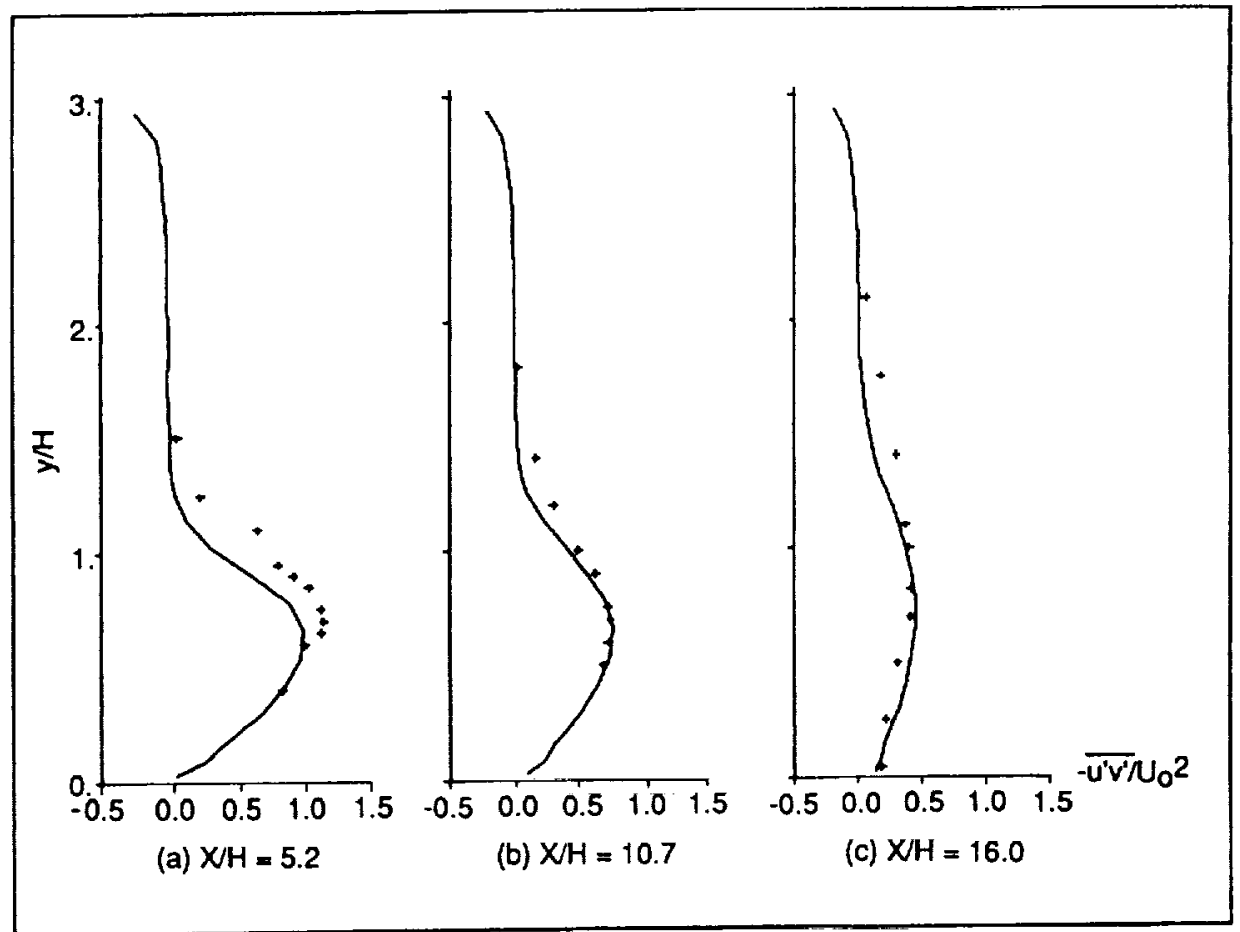

-- : comput. result, + : exp't data.

Figure A-5. Reynolds stress profiles for backward-facing step flow.

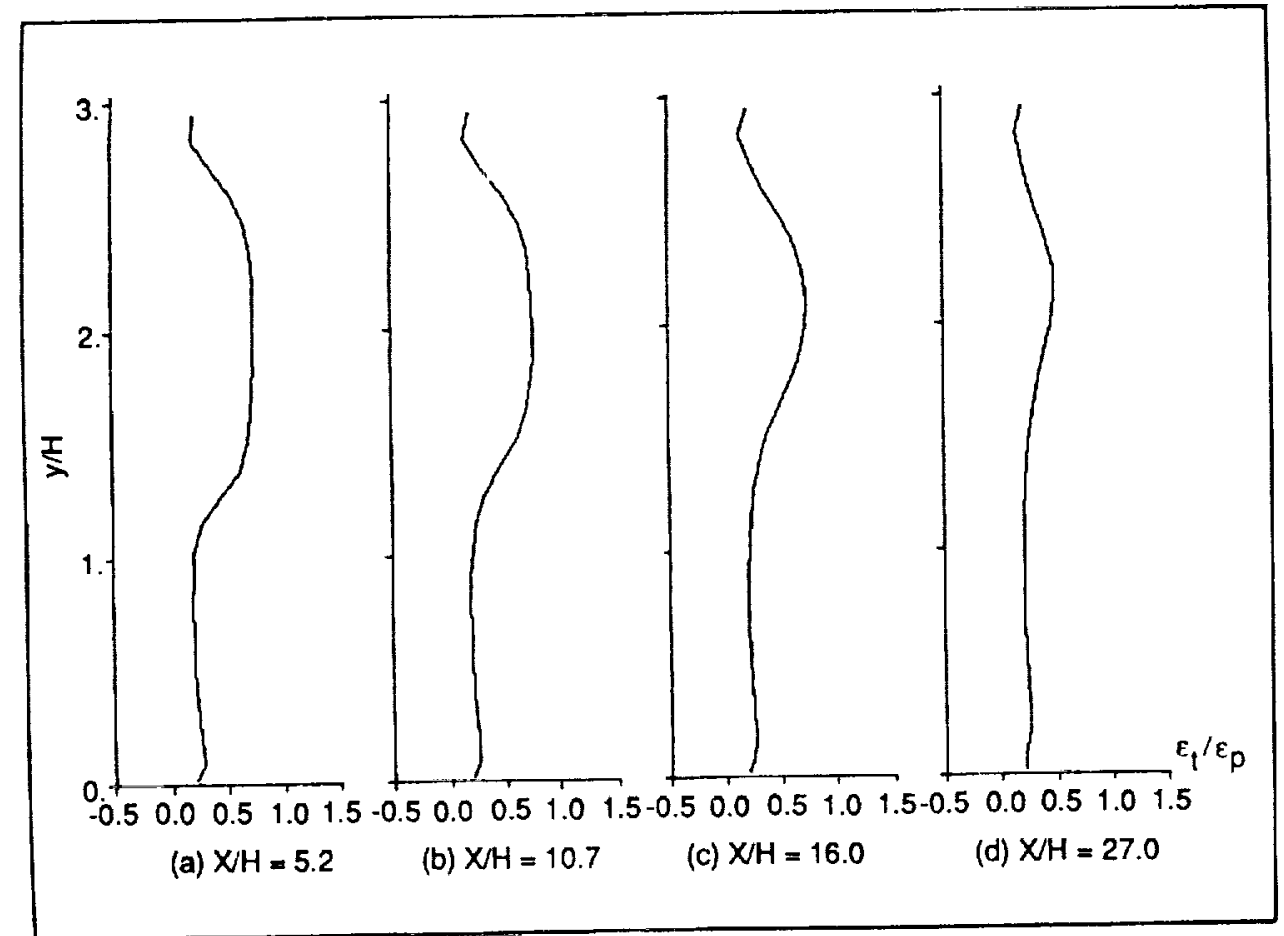

Figure A-6. The ratio of dissipation rate to energy transfer rate for the backward-facing step flow. 


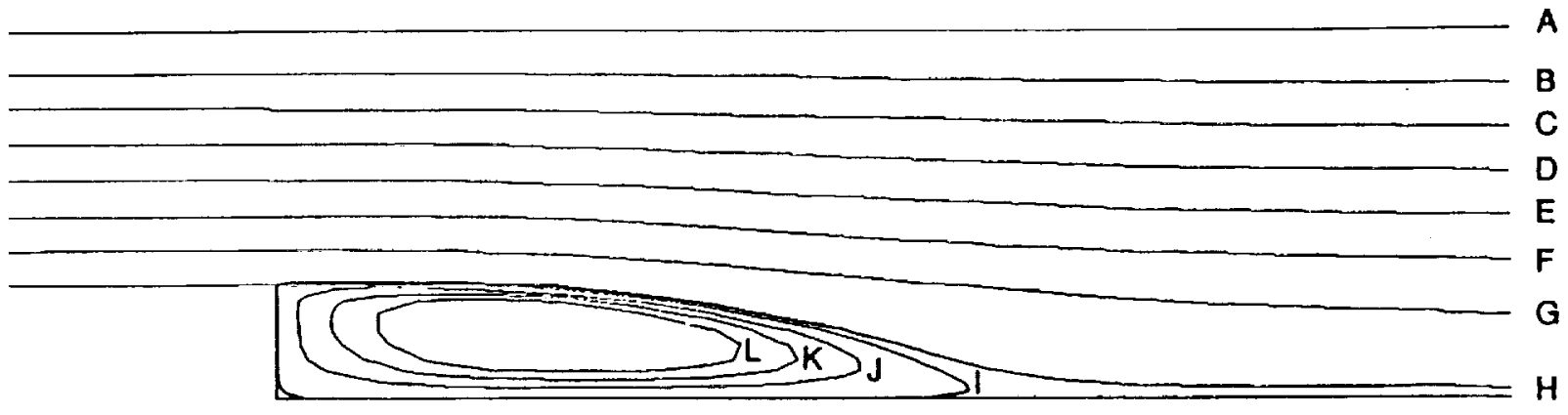

Figure A-7. Streamline contour for backward-facing step flow for $\sigma_{\mathrm{kp}}=\sigma_{\mathrm{kt}}=1.0$ and $\sigma_{\varepsilon p}=\sigma_{\varepsilon t}=1.3$.

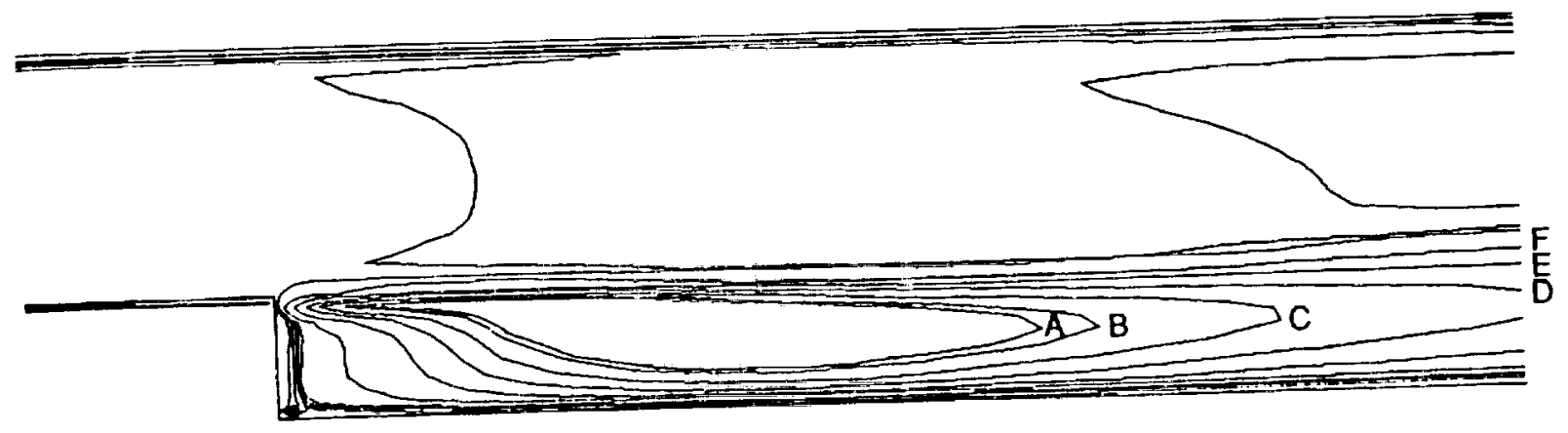

Figure A-8. Turbulent kinetic energy contour for backward-facing step flow, $\sigma_{\mathrm{kp}}=\sigma_{\mathrm{kt}}=1.0$ and $\sigma_{\varepsilon \mathrm{p}}=\sigma_{\varepsilon t}=1.3$. 


\section{A-2-2. A Confined Swirling Jet}

For confined swirling jet computations, the inlet boundary conditions were obtained directly and/or by curve-fitting the experimental data [23] at $0.005 \mathrm{~m}$ downstream of the expansion corner in order to reduce uncertainties in the inlet boundary condition. The inlet boundary condition for the ratios of $\mathrm{k}_{\mathrm{t}} / \mathrm{k}_{\mathrm{p}}$ and $\varepsilon_{\mathrm{t}} / \varepsilon_{\mathrm{p}}$ has been obtained by using equation (19). A 42 by 30 grid with concentrations of nodes in the recirculation regions, in the entrance region, and near the wall was used for the calculation. The streamline and the turbulent kinetic energy contours are shown in Figures A.9 and A.10, respectively; and the development of the axial velocity along the center line is shown in Figure A.11. The predicted strength and size of the central recirculation zone compared favorably with the experimental data. The location and shape of the central and corner recirculation zones shown in Figure A.9 compared more favorably with experimental data than those obtained by using the standard $\mathbf{k}-\varepsilon$ turbulence model and the two other $\mathrm{k}-\varepsilon$ type turbulence models which include the swirl-related modifications [24]. Comparison of the calculated mean axial and swirl velocity profiles with the experimental data are presented in Figures A-12 and A-13, where it is shown that the calculated mean velocity profile mimic the exhibited data trend and that these velocities are in good agreement with measurements at most of the locations. The predicted axial velocity profiles were skewed toward the wall, the trend of which is in good agreement with that of the measured data. At further downstream locations, the computed swirl velocity exhibited a slightly premature decay toward a forced vortex profile. The discrepancies in these predictions can be partially attributed to the wall functions used. The free vortex swirler used in the experimental study [23] generated a very unstable flow field. The equilibrium assumption underlying in the wall functions may be doubtful in this situation. Nevertheless, the suitability of the present turbulence model for complex turbulent flows has been partly demonstrated through these computational results.

The r.m.s. values of the fluctuating axial velocity $\left(\overline{u^{\prime 2}}\right)$ at various downstream locations are compared with experimental data in Figure A-14. The computational results showed similar trend with that of experimental data, but the magnitude of the r.m.s. values of the fluctuating axial velocity was found to be under-predicted. These under-predictions may be due to the isotropic turbulence assumption used in estimating the r.m.s, value of the fluctuating axial velocity from the computed turbulent kinetic energy.

The ratios of dissipation rate to energy transfer rate at the same axial locations are shown in Figure A-15. It can be seen that the ratio is smaller in the high turbulence region than in the low turbulence region, which was the same for all the flow cases considered herein. At far downstreams, the flow approached fully developed pipe flow state and the ratio $\left(\varepsilon_{\mathrm{t}} / \varepsilon_{\mathrm{p}}\right)$ became almost uniform in the radial direction.

The streamline and the turbulent kinetic energy contours obtained by using $\sigma_{\mathrm{kp}}=\sigma_{\mathrm{kt}}=1.0$ and $\sigma_{\varepsilon p}=\sigma_{\varepsilon t}=1.3$ are shown in Figures $\mathrm{A}-16$ and $\mathrm{A}-17$. Only very insignificant changes were detected in mean features of the flow such as the streamline contour and mean velocity profiles. Slight difference was found in the turbulent kinetic energy contours. The computational results obtained by using $\sigma_{\mathrm{kp}}=\sigma_{\mathrm{kt}}=1.0$ and $\sigma_{\varepsilon p}=\sigma_{E t}=1.3$ were found to be more diffusive than those obtained by using the other set of coefficients, however, the differences were insignificant in general. 


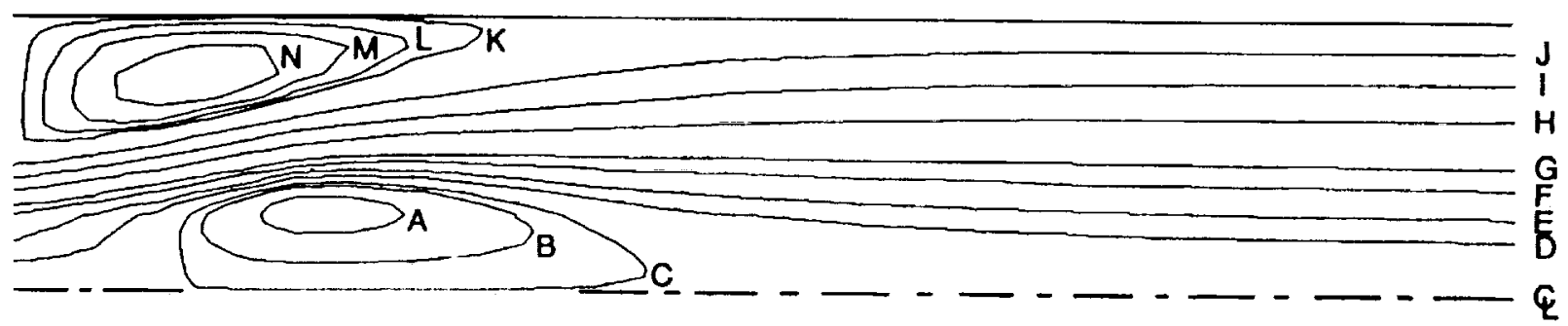

Figure A-9. Streamline contour for confined swirling jet.

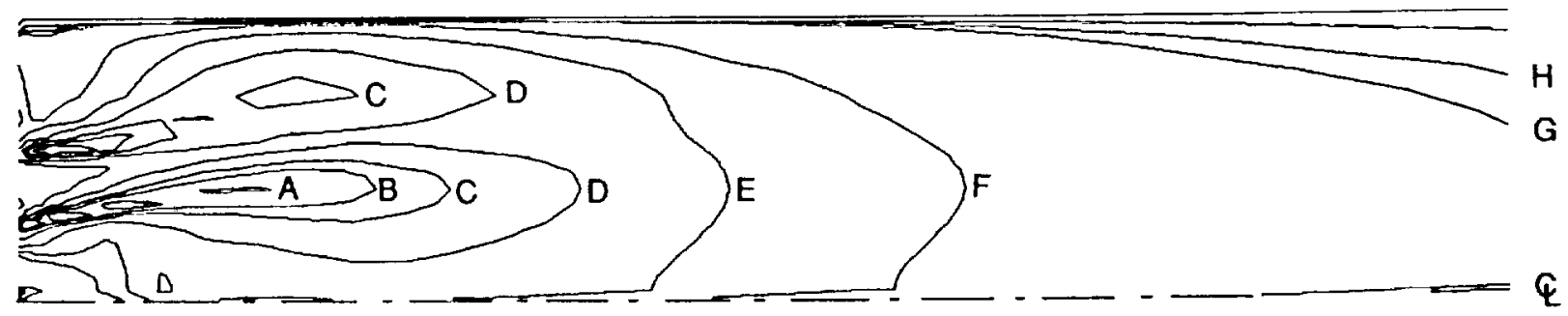

Figure A-10. Turbulent kinetic energy contour for confined swirling jet.

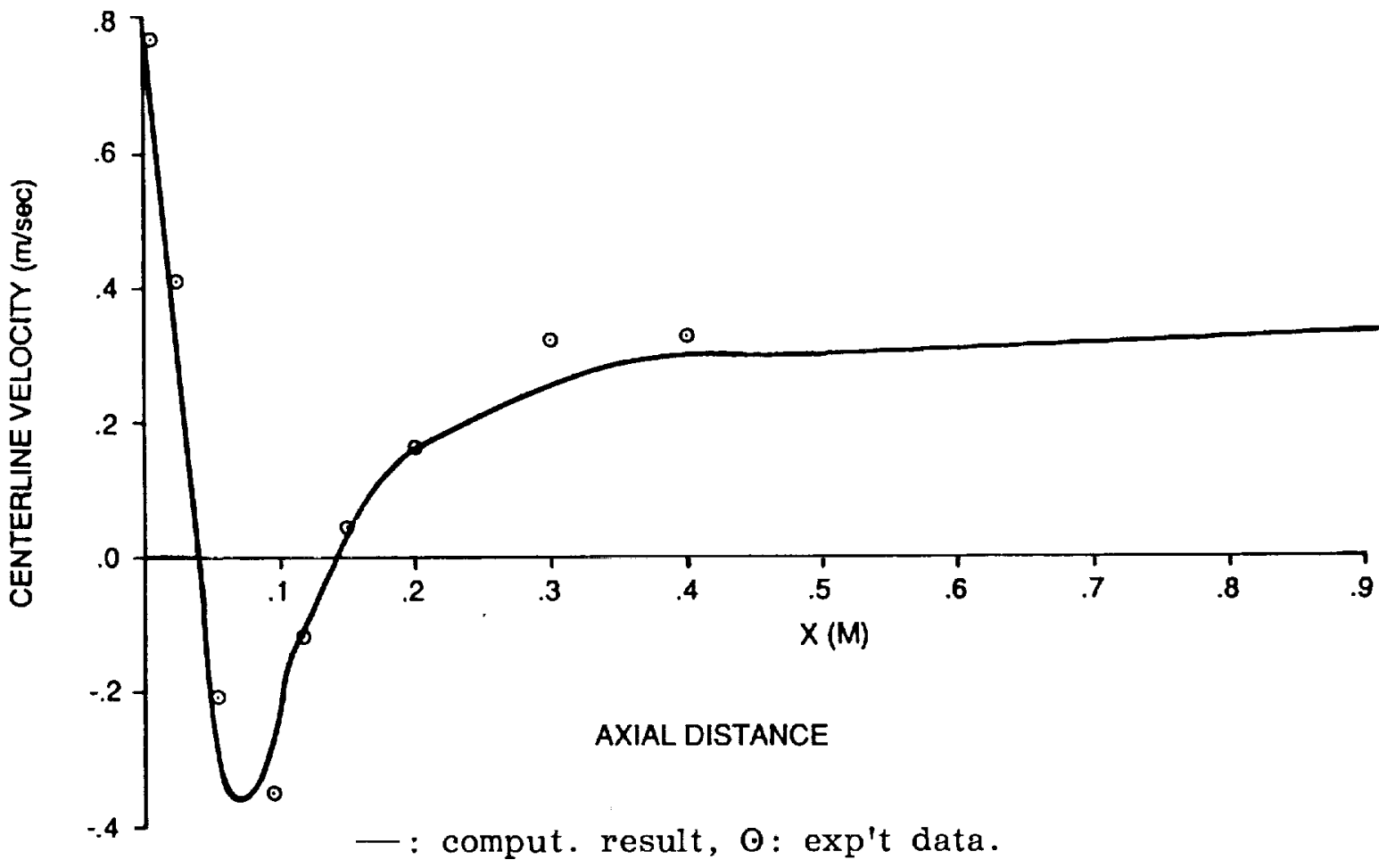

Figure A-11. Development of the axial mean velocity along the center line for confined swirling jet. 


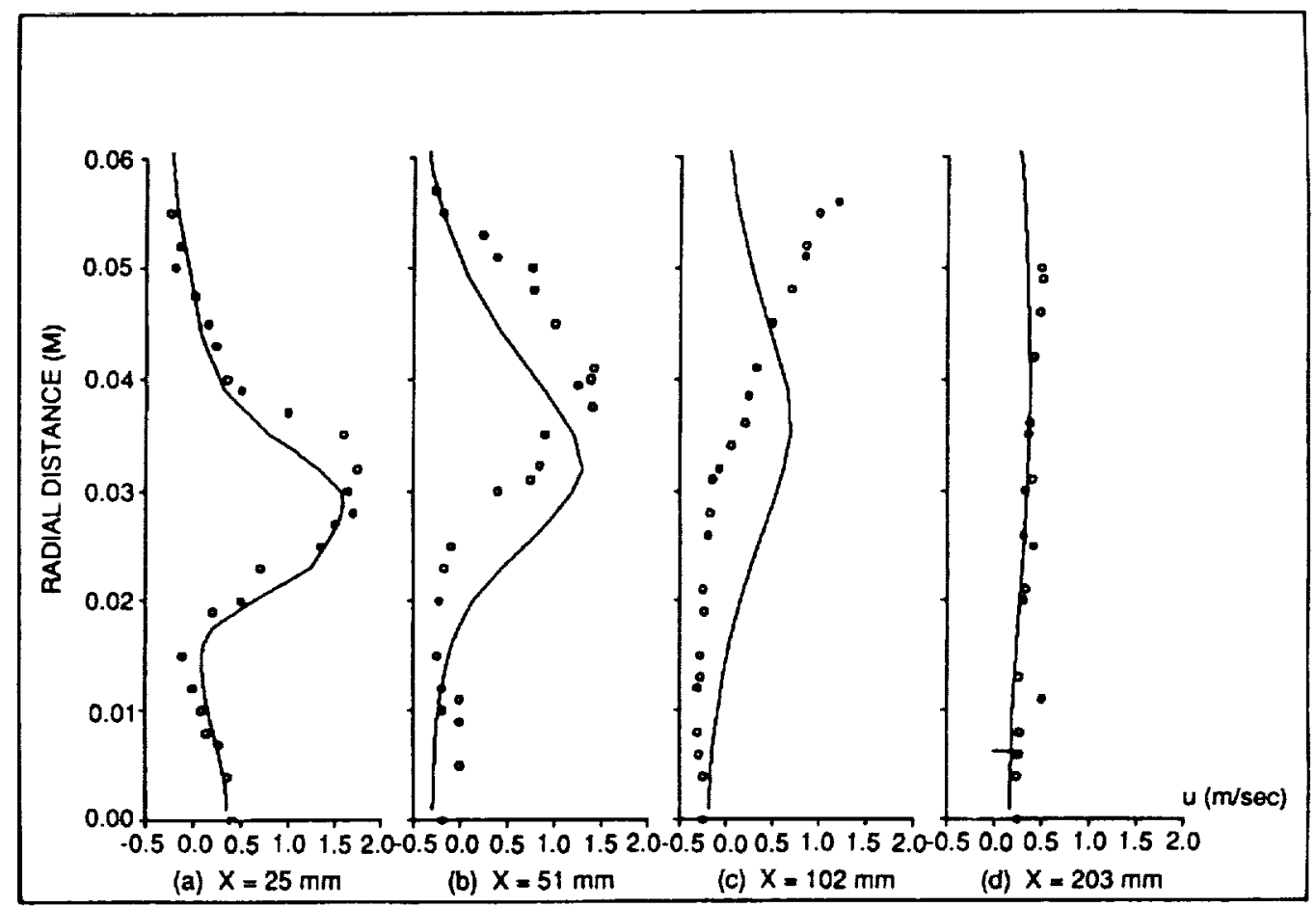

- : comput. result, o: exp't data.

Figure A-12. Axial velocity profiles of the confined swirling jet.

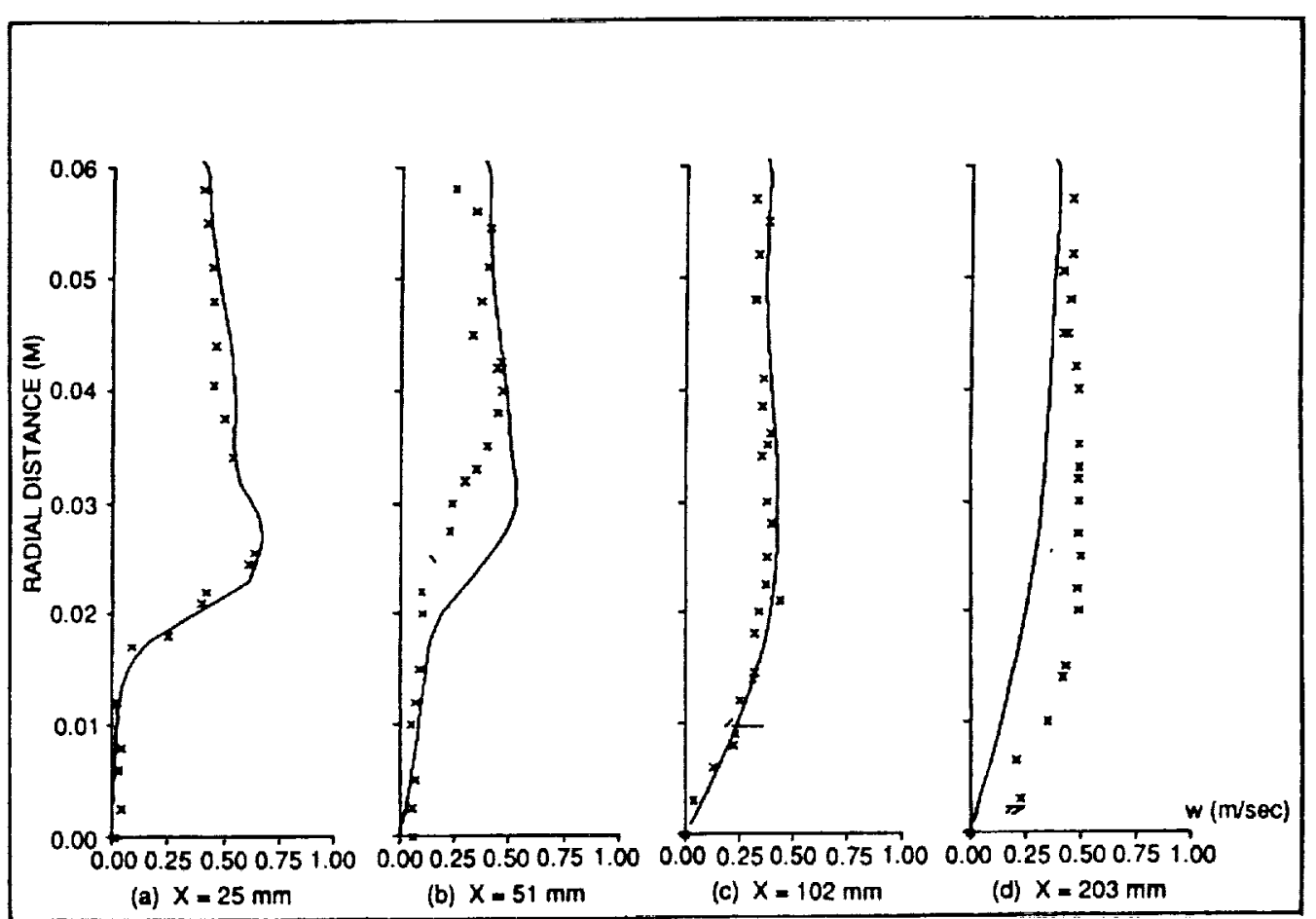

-: comput. result, $x$ : exp't data.

Figure A-13. Swirl velocity profiles of the confined swirling jet. 


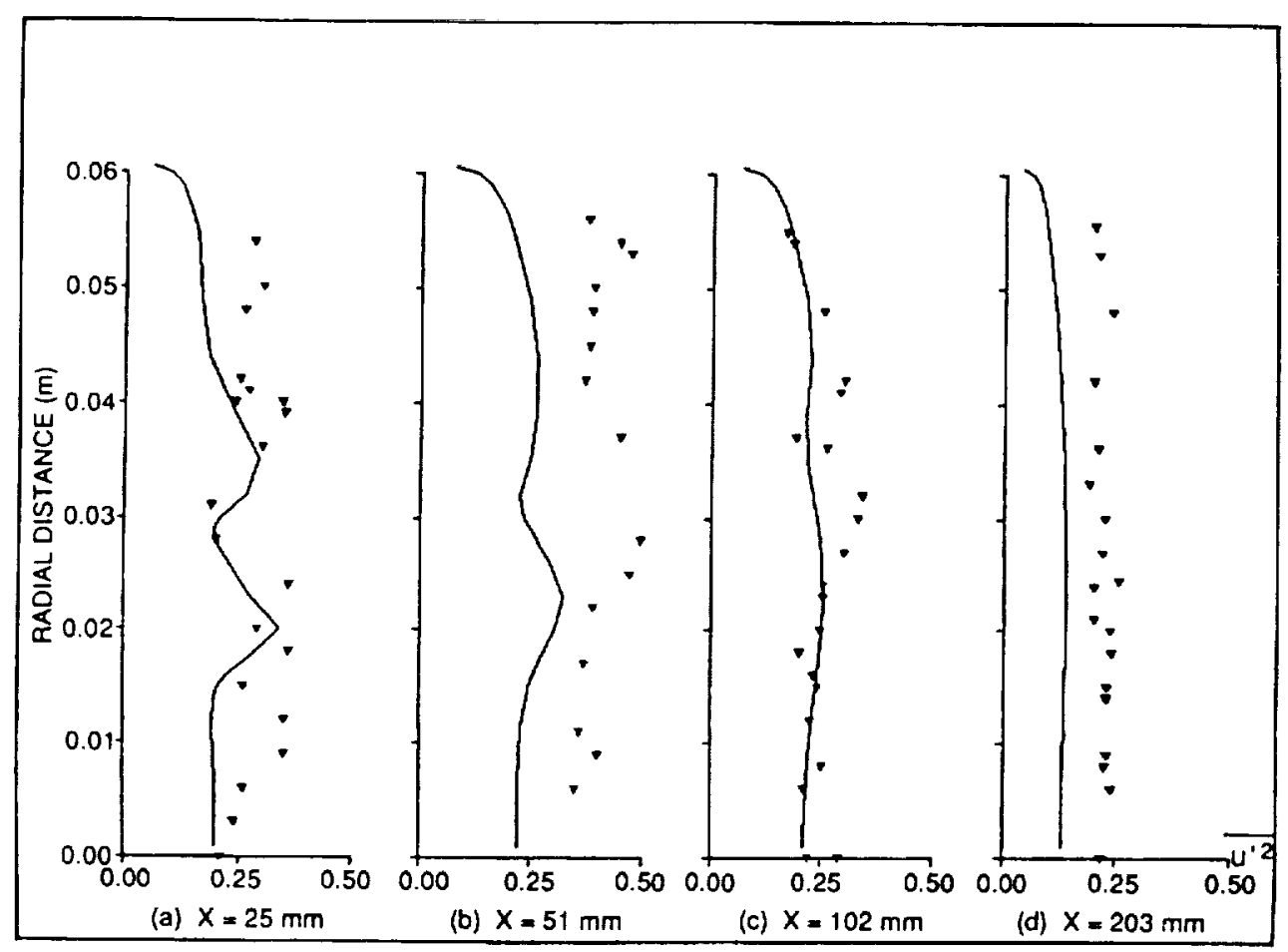

- comput. result, $\nabla$ : exp't data.

Figure A-14. R.M.S. values of the fluctuating axial velocity.

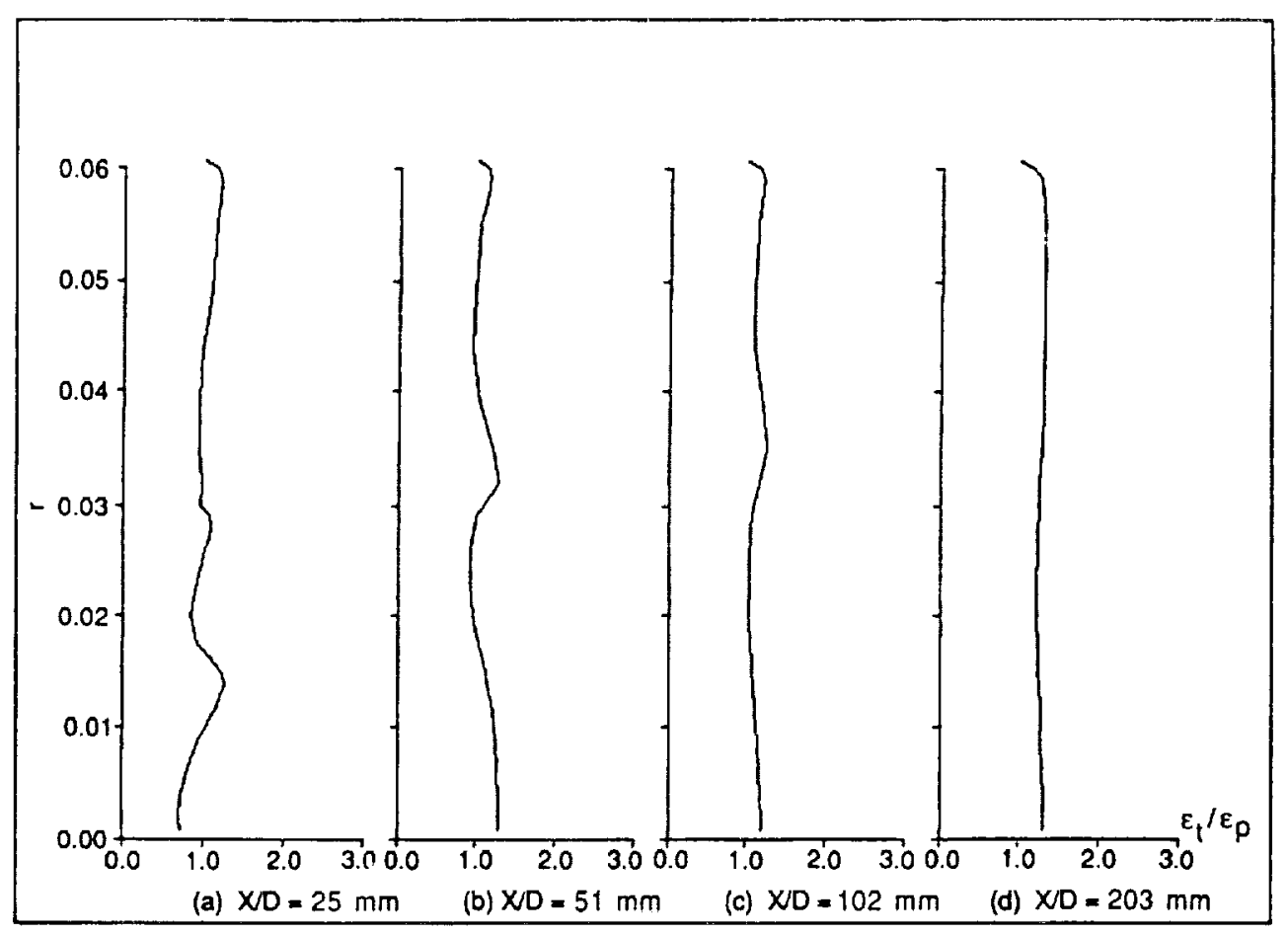

Figure A-15. The ratio of dissipation rate to energy transfer rate for confined swirling jet. 


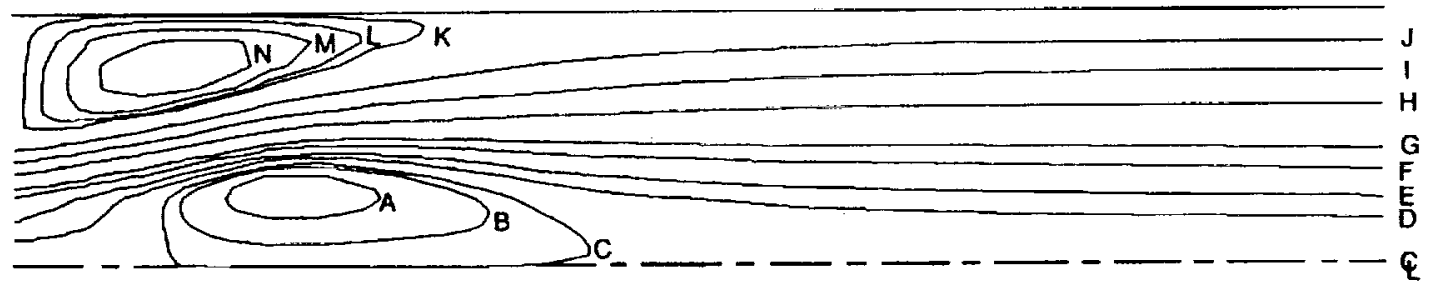

Figure A-16. Streamline contour for confined swirling jet, $\sigma_{\mathrm{kp}}=\sigma_{\mathrm{kt}}=1.0$ and $\sigma_{\mathrm{Ep}}=\sigma_{\varepsilon t}=1.3$.

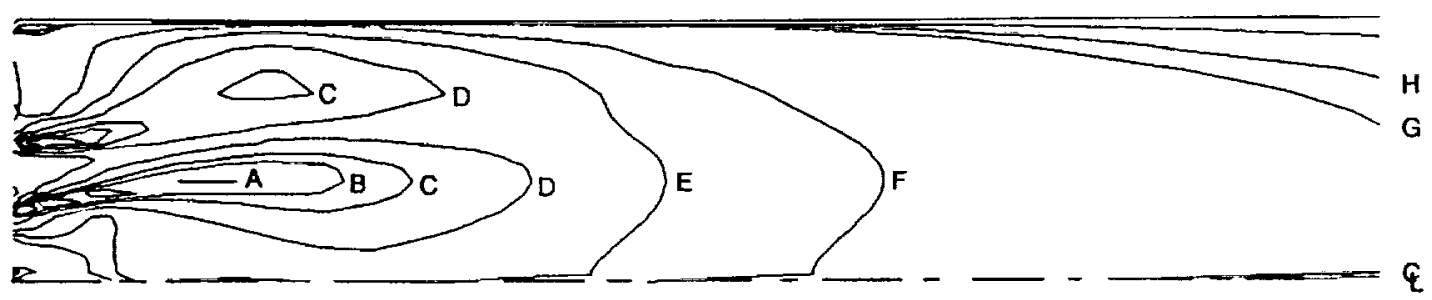

Figure A-17. Turbulent kinetic energy contour for confined swirling jet, $\sigma_{\mathrm{kp}}=\sigma_{\mathrm{kt}}=1.0$ and $\sigma_{\varepsilon p}=\sigma_{\varepsilon t}=1.3$. 
TABLE A-1. CONTOUR LABELS FOR BACKWARD-FACING STEP FLOW

(a) Streamline $\left(\psi^{*}\right)$

\begin{tabular}{|cc|cl|cl|}
\hline Label & $\boldsymbol{\psi}$ & Label & $\psi$ & Label & \multicolumn{1}{|c|}{$\boldsymbol{\psi}$} \\
\hline $\mathrm{A}$ & 0.0 & $\mathrm{E}$ & 0.4 & $\mathrm{I}$ & 0.6081 \\
$\mathrm{~B}$ & 0.1 & $\mathrm{~F}$ & 0.5 & $\mathrm{~J}$ & 0.685 \\
$\mathrm{C}$ & 0.2 & $\mathrm{G}$ & 0.6 & $\mathrm{~K}$ & 0.69 \\
$\mathrm{D}$ & 0.3 & $\mathrm{H}$ & 0.6767 & $\mathrm{~L}$ & 0.695 \\
\hline
\end{tabular}

* : The streamline data are based on the normalized velocity.

(b) Turbulent Kinetic Energy $\left(k^{\star *}\right)$

\begin{tabular}{|cc|cc|cc|}
\hline Label & $\mathbf{k}$ & Label & k & Label & k \\
\hline A & 0.0394 & C & 0.0292 & E & 0.0146 \\
B & 0.0365 & D & 0.0219 & F & 0.0073 \\
\hline
\end{tabular}

** : The turbulent kinetic energy has been normalized by $\mathrm{U}_{0}{ }^{2}$, where $U_{0}(=18.5 \mathrm{~m} / \mathrm{sec})$ is the inlet velocity.

TABLE A-2. CONTOUR LABELS FOR CONFINED SWIRLING JET

(a) Streamline $\left(\psi^{*}\right)$

\begin{tabular}{|cc|cc|cc|}
\hline Label & $\psi$ & Label & $\psi$ & Labe1 & $\psi$ \\
\hline A & $-0.25 \mathrm{E}-4$ & $\mathrm{~F}$ & $0.80 \mathrm{E}-4$ & $\mathrm{~K}$ & $0.60 \mathrm{E}-3$ \\
B & $-0.75 \mathrm{E}-5$ & $\mathrm{G}$ & $0.12 \mathrm{E}-3$ & $\mathrm{~L}$ & $0.62 \mathrm{E}-3$ \\
C & $-1.0 \mathrm{E}-7$ & $\mathrm{H}$ & $0.24 \mathrm{E}-3$ & $\mathrm{M}$ & $0.65 \mathrm{E}-3$ \\
D & $0.2 \mathrm{E}-4$ & $\mathrm{I}$ & $0.36 \mathrm{E}-3$ & $\mathrm{~L}$ & $0.69 \mathrm{E}-3$ \\
E & $0.4 \mathrm{E}-4$ & $\mathrm{~J}$ & $0.48 \mathrm{E}-3$ & & \\
\hline
\end{tabular}

* : The streamline data are based on the physical velocity.

(b) Turbulent Kinetic Energy $\left(\mathrm{k}, \mathrm{m}^{2} / \mathrm{sec}^{2}\right)$

\begin{tabular}{|cc|cc|cc|}
\hline Label & $k$ & Label & $k$ & Label & $k$ \\
\hline A & 0.15 & D & 0.08 & E & 0.01 \\
B & 0.13 & E & 0.05 & F & 0.008 \\
C & 0.11 & F & 0.03 & & \\
\hline
\end{tabular}




\section{REFERENCES}

1. Hanjalic, K., Launder, B. E., and Schiestel, R .: Multiple-Time-Scale Concepts in Turbulent Shear Flows. Eds. L. J. S. Bradbury et al., Turbulent Shear Flows, Vol. 2, Springer-Verlag, New York, 1980, pp. 36-49.

2. Fabris, G., Harsha, P. T., and Edelman, R. B.: Multiple-Scale Turbulence Modeling of Boundary Layer Flows for Scramjet Applications. NASA CR-3433, 1981.

3. Schiestel, R.: Multiple-Scale Concept in Turbulence Modelling, I. MultipleScale Model for Turbulence Kinetic Energy and Mean Square of Passive Scalar Fluctuations. Journal de Mechanique Theorique et Appliquee, Vol. 2, No. 3, 1983, pp. 417-449.

4. Schiestel, R.: Multiple-Scale Concept in Turbulence Modelling, II. Reynolds Stresses and Turbulent Fluxes of a Passive Scalar, Algebraic Modelling and Simplified Model Using Boussinesq Hypothesis. Journal de Mechanique Theorique et Appliquee, Vol. 2, No. 4, 1983, pp. 601-628.

5. Kim, S.-W., and Chen, Y.-S.: A Finite Element Computation of Turbulent Boundary Layer Flows with an Algebraic Stress Turbulence Model. To appear in Comput. Meth. Appl. Mech. Engrg.

6. Kim, S.-W., and Chen, Y.-S.: Computation of Turbulent Boundary Layer Flows with an Algebraic Stress Turbulence Model. NASA CR-178967, 1986.

7. Launder. B. E.: A Generalized Algebraic Stress Transport Hypothesis. J. AIAA, Vol. 20, 1982, pp. 436-437.

8. Rodi, W.: The Prediction of Free Boundary Layers by Use of a Two-Equation Model of Turbulence. Ph.D. Thesis, University of London, London, 1972.

9. Kim, S.-W., and Payne, F. R.: Finite Element Analysis of Incompressible Laminar Bounday Layer Flows. Int. J. Nume. Meth. Fluids, Vol. 5, 1985, pp. 545-560.

10. Kim, S.-W.: Finite Element Analysis of Incompressible Laminar Boundary Layer Flows. Ph.D. Thesis, A. E. Dept., Univ. of Texas at Arlington, 1983.

11. Pope, S. B.: An Explanation of the Turbulent Round-Jet/Plane-Jet Anomaly . J. AIAA, Vol. 16, 1978, pp. 279-281.

12. Hanjalic, K., and Launder, B. E.: Sensitizing the Dissipation Equation to Irrotational Strains. Transactions of ASME, Vol. 102, 1980, pp. 34-40.

13. Patel, V. C., Rodi, W., and Scheuerer, G.: Turbulence Models for Near Wall and Low Reynolds Number Flows; A Review. J. AIAA, Vol. 23, 1985, pp. 13081319 .

14. Laufer, J.: Investigation of Turbulent Flow in a Two-Dimensional Channel. NACA CR-1053, 1949. 
15. Bradbury, L. J. S.: The Structure of a Self-Preserving Turbulent Plane Jet. J. Fluid Mech., Vol. 23, 1965, pp. 31-64.

16. Irwin, H. P. A. H.: Measurements in a Self-Preserving Plane Wall Jet in a Positive Pressure Gradient. J. Fluid Mech., Vol. 61, 1973, pp. 33-63.

17. Ljuboja, M., and Rodi, W.: Calculation of Turbulent Wall Jets with an Algebraic Stress Model. Transactions of the ASME, Vol. 102, 1980, pp. 350-356.

18. Tsiolakis, E. P., Krause, E., and Muller, U. R.: Turbulent Boundary LayerWake Interaction. Turbulent Shear Flow, Vol. 4, Eds. Bradbury, L. J. S., et al., Springer-Verlag, New York, 1983.

19. Harlow, F. H., and Nakayama, P. I.: Transport of Turbulence Energy Decay Rate. Los Alamos Sci. Lab., LA-3854, 1968.

20. Harris, V. G., Graham, J. A. H., and Corrsin, S.: Further Experiments in Nearly Homogeneous Turbulent Shear Flow. J. Fluid Mech., Vol. 81, 1977, pp. 657-687.

21. Gosman, A. D., and Ideriah, F. J. K.: TEACH-T. Dept. of Mech. Eng., Imperial College, London, 1978.

22. Kim, J., Kline, S. J., and Johnston, J. P.: Investigation of a Reattaching Turbulent Shear Layer: Flow Over a Backward-Facing Step. J. Fluid Eng. Vol. 102, 1980, pp. 302-308.

23. Roback, R., and Johnson, B. V.: Mass and Momentum Turbulent Transport Experiments with Confined Swirling Coaxial Jets. NASA CR-168252, 1983.

24. Kline, S. J., et al., eds.: The 1980-1981 AFOSR-HTTM Stanford Conference on Complex Turbulent Flows. Vol. I and III, 1981. 



\section{APPROVAL}

\section{A MULTIPLE-TIME-SCALE TURBULENCE MODEL BASED ON \\ VARIABLE PARTITIONING OF TURBULENT \\ KINETIC ENERGY SPECTRUM \\ By S. W. Kim}

The information in this report has been reviewed for technical content. Review of any information concerning Department of Defense or nuclear energy activities or programs has been made by the MSFC Security Classification Officer. This report, in its entirety, has been determined to be unclassified.

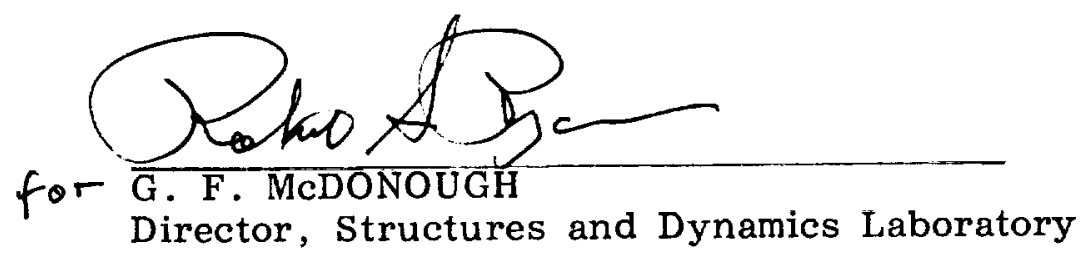




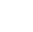


TECHNICAL REPORT STANDARD TITLE PAGE 1. REPORT NO.

NASA CR- 179222

2. GOVERNMENT ACCESSION NO.

3. RECIPIENT'S CATALOG NO.

4. TITLE AND SUBTITLE

A Multiple-Time-Scale Turbulence Model Based on Variable Partitioning of Turbulent Kinetic Energy Spectrum

7. AUTHOR(S)

S. -W. Kim* and C. - P. Chen* *

9. PERFORMING ORGANIZATION NAME AND AODRESS

George C. Marshall Space Flight Center

Marshall Space Flight Center, Alabama 35812

12. SPONSORING AGENCY NAME AND ADDRESS

National Aeronautics and Space Administration

Washington, D.C. 20546

5. REPORT DATE

November 1987

6. PERFORMING ORGANIZATION CCIDE

8. PERFORMING ORGANIZATION REPORI \#

10. WORK UNIT. NO.

11. CONTRACT OR GRANT NO.

NAS 8- 35918

13. TYPE OF REPORI \& PERIOD COVERED

Contractor Report

1.4. SPONSORING AGENCY CODE

15. supplementary notes Contraff Monitorjight Ċentertes, Systems Dynamics Lab., *Universities space Research Association

$\star \star$ Dept . of Mechanical Engineering, University of Alabama in Huntsville.

i6. ABSTRACT

A multiple-time-scale turbulence model of a single point closure and a simplified split-spectrum method is presented in this paper. In the model, the effect of the ratio of the production rate to the dissipation rate on eddy viscosity is modeled by use of the multiple-time-scales and a variable partitioning of the turbulent kinetic energy spectrum. The concept of a variable partitioning of the turbulent kinetic energy spectrum and the rest of the model details are based on the previously reported algebraic stress turbulence model. Example problems considered include: a fully developed channel flow, a plane jet exhausting into a moving stream, a wall jet flow, and a weekly coupled wake-boundary layer interaction flow. The computational results compared favorably with those obtained by using the algebraic stress turbulence model as well as experimental data. The present turbulence model, as well as the algebraic stress turbulence model, yielded significantly improved computational results for the complex turbulent boundary layer flows, such as the wall jet flow and the wake-boundary layer interaction flow, compared with available computational results obtained by using the standard $\mathrm{k}-\varepsilon$ turbulence model.

17. KEY WORDS Multiple-Time-Scale Turbulence Model, Algebraic Stress Turbulence Model, Turbulent Wall Jet, Turbulent Wake-

Boundary Layer Interaction Flow, Turbulent Backward-Facing Step Flow, Confined Swirling Jet, Finite Element Method, ControlVolume Based Finite Difference Method
18. DISTRIBUTION STATEMENT

Unclassified/Unlimited

9. SECURITY CLASSIF. (of thle report)

20. SECURITY CLASSIF. (of this gage)

Unclassified

Unclassified

21. NO. OF PAGES

41

22. PRICE

NTIS 
